\title{
Antarctic Mesoscale Prediction System (AMPS): A Case Study from the 2000-01 Field Season*
}

\author{
David H. BRomwich AND ANDREw J. Monaghan \\ Polar Meteorology Group, Byrd Polar Research Center, and Atmospheric Sciences Program, Department of Geography, \\ The Ohio State University, Columbus, Ohio \\ JORDAN G. POWERS \\ Mesoscale and Microscale Meteorology Division, National Center for Atmospheric Research, Boulder, Colorado \\ John J. CASSANO ${ }^{+}$AND He-Lin WeI \\ Polar Meteorology Group, Byrd Polar Research Center, The Ohio State University, Columbus, Ohio \\ YING-HwA KuO \\ Mesoscale and Microscale Meteorology Division, National Center for Atmospheric Research, Boulder, Colorado \\ Andrea Pellegrini \\ ENEA Antarctic Project, Rome, Italy
}

(Manuscript received 2 July 2001, in final form 28 November 2001)

ABSTRACT

\begin{abstract}
To support the forecasting needs of the United States Antarctic Program at McMurdo, Antarctica, a special numerical weather prediction program, the Antarctic Mesoscale Prediction System (AMPS), was established for the 2000-01 field season. AMPS employs the Polar MM5, a version of the fifth-generation Pennsylvania State University-NCAR Mesoscale Model (MM5) that has physics modifications for polar environments. This study assesses the performance of AMPS in forecasting an event of mesoscale cyclogenesis in the western Ross Sea during 13-17 January 2001. Observations indicate the presence of a complex trough having two primary mesoscale lows that merge to the east of Ross Island shortly after 0700 UTC 15 January. In contrast, AMPS predicts one primary mesoscale low throughout the event, incorrectly placing it until the 1800 UTC 15 January forecast, when the observed system carries a prominent signature in the initialization. The model reproduces the evolution of upper-level conditions in agreement with the observations and shows skill in resolving many small-scale surface features common to the region (i.e., katabatic winds; lows and highs induced by wind/topography). The AMPS forecasts can rely heavily on the representation of surface lows and upper-level forcing in the first-guess fields derived from NCEP's Aviation Model (AVN). Furthermore, even with relatively high spatial resolution, mesoscale models face observation-related limitations on performance that can be particularly acute in Antarctica.
\end{abstract}

\section{Background}

The United States Antarctic Program (USAP) operating out of McMurdo station, Antarctica, relies heavily on weather forecasts for the coordination of short-term

\footnotetext{
* Byrd Polar Research Center Contribution Number 1238.

+ Current affiliation: CIRES, University of Colorado, Boulder, Colorado.
}

Corresponding author address: Dr. David H. Bromwich, Polar Meteorology Group, Byrd Polar Research Center, The Ohio State University, 1090 Carmack Rd., Columbus, OH 43210.

E-mail: bromwich@polarmet1.mps.ohio-state.edu local field logistics, as well as flight operations from Christchurch, New Zealand. Flights from New Zealand take up to $8 \mathrm{~h}$ to reach McMurdo-enough time for the weather to change dramatically in this terrain-dominated area with coastal mountains in excess of $4000 \mathrm{~m}$ high. This has the potential to endanger passengers and cargo, and can be very expensive in the case that flights must turn back to Christchurch. In addition, there is an increasing demand for operations in the harsh winter months, including flights for scientific and rescue purposes. These issues have generated a contemporary interest in improving forecasting capabilities in the Antarctic. 


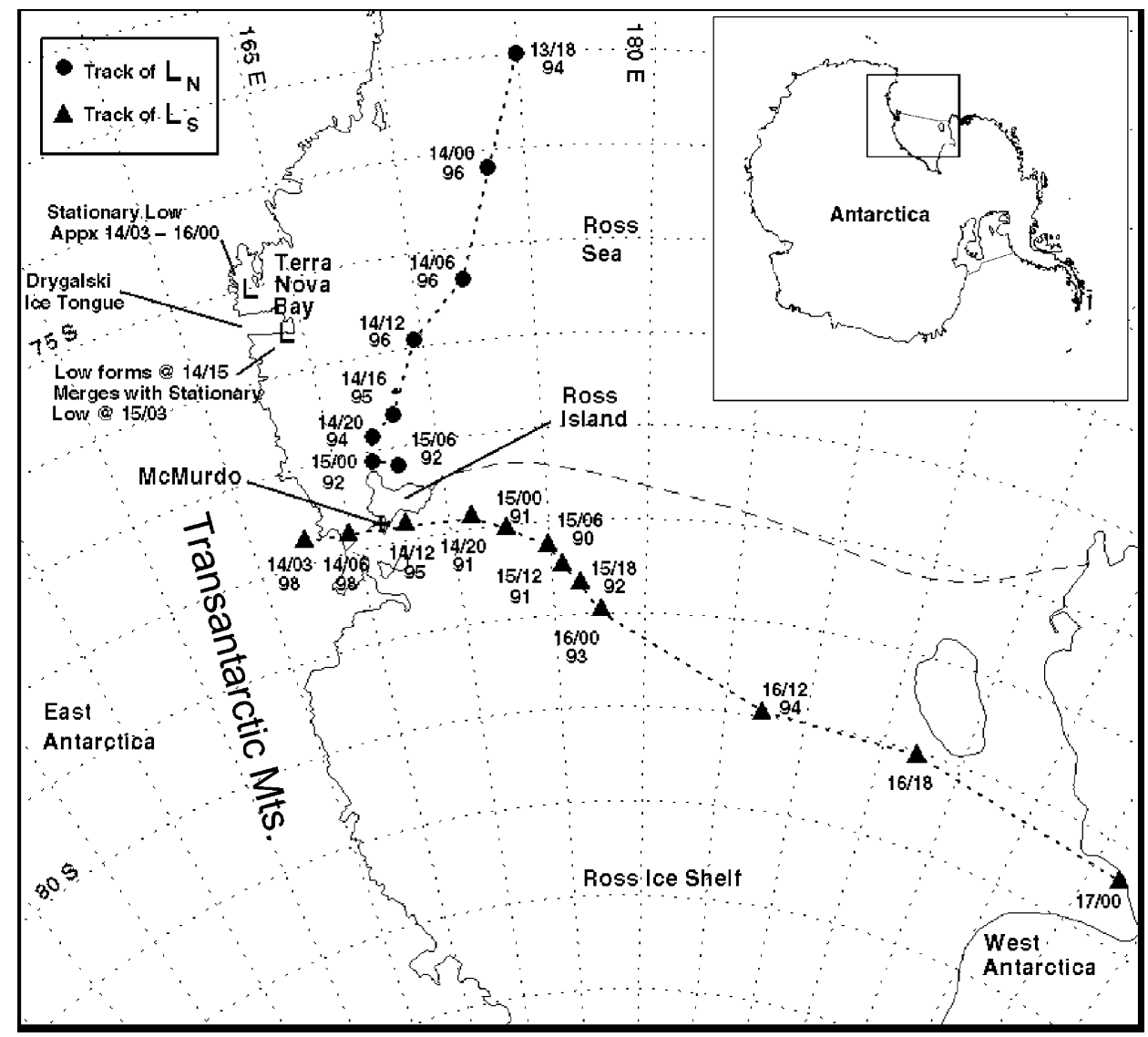

FIG. 1. Study area for a weather system occurring in the Ross Sea region, 13-17 Jan 2001.

In May 2000 the Antarctic Weather Forecasting Workshop was held at the Byrd Polar Research Center of The Ohio State University to review the state of the science of weather forecasting over the Antarctic. There, it was formally recognized that guidance from numerical forecast models is critical to forecasters at McMurdo station to bridge the gap between current observations and future weather. While a few models [e.g., the National Centers for Environmental Prediction (NCEP) Aviation Model (AVN), the Fleet Numerical Meteorology and Oceanography Center (FNMOC) Navy Operational Global Atmospheric Prediction System (NOGAPS)] were yielding products covering Antarctica, their guidance was felt to be of limited utility. The reasons were (i) horizontal resolution inadequate to resolve mesoscale features crucially affecting short-term (6-24 h) forecasting and flight operations, (ii) inadequate representation of physical properties unique to the Antarctic troposphere and boundary layer, (iii) poor representation of Antarctic topography and surface features, and (iv) inadequate initial conditions, reflecting the sparse observational network in the high southern latitudes. A key conclusion from the workshop was that focused efforts were needed immediately to improve numerical weather prediction (NWP) for the Antarctic through an
Antarctic mesoscale modeling initiative (Bromwich and Cassano 2000, 2001). Foremost among numerous recommendations to the National Science Foundation for improving NWP capabilities for the USAP was the implementation of a higher-resolution Antarctic forecast domain (i.e., grid sizes $\leq 15 \mathrm{~km}$ ) for the 2000-01 USAP field season (October-February). In light of this concern, the Antarctic Mesoscale Prediction System (AMPS) has been developed. AMPS centers around a real-time implementation of the Polar MM5, a version of the fifth-generation Pennsylvania State UniversityNational Center for Atmospheric Research (NCAR) Mesoscale Model (MM5), modified to represent parameterizations over extensive ice sheets (Bromwich et al. 2001; Cassano et al. 2001; Guo et al. 2003). Since October 2000, AMPS has been furnishing twice-daily numerical guidance for both Antarctica and the McMurdo station area (Fig. 1). The project has completed its first field season, and the system has been eagerly received by the forecasters at McMurdo. This program serves research planners, polar meteorologists at McMurdo and elsewhere, and flight forecasters responsible for supporting flights between Christchurch, New Zealand, and McMurdo station. The goals of the AMPS project include the following: 
- to provide real-time mesoscale and synoptic forecast products for Antarctica, tailored to the needs of field forecasters at McMurdo station;

- to improve and incorporate physical parameterizations suitable for the Antarctic region into the forecast model (the MM5);

- to perform qualitative and quantitative forecast verification to assess the system's accuracy and to identify areas for model improvement; and

- to stimulate close collaboration between forecasters, modelers, and researchers by making the forecast products and the model output available to the community through a Web interface, public archive, and workshop/conference interactions.

In support of these goals, this paper investigates a storm occurring in the western Ross Sea between 13 and 17 January 2001 (Fig. 1) and, specifically, the skill of the Polar MM5 in forecasting this event. The subsequent text begins with a synopsis of the data used in the study. Next, we examine several phenomena that occur, including the low pressure systems in the region, katabatic and barrier winds, and weather at Williams Field (the primary airstrip for operations at McMurdo). Then, the forecast performance of the Polar MM5 is analyzed. Finally, a summary of the goals and findings of the study is given, as well as the resulting recommendations.

\section{Data}

The complexity of this event requires the integration of nearly all available data from the surface and upper levels. The surface analysis utilizes data from automatic weather stations (AWS), Automatic Geophysical Observatory (AGO) sites, ship observations, and satellite images. AWS observations are from USAP sites, made available by the University of Wisconsin's Space Science and Engineering Center (SSEC), and also from the Italian Antarctic Program, which focuses on sites in and around Terra Nova Bay (TNB). AGO sites, maintained by Augsburg University, are located on the high, interior plateau of Antarctica. Wind, pressure, and temperature data from these AGO sites are used to depict the geopotential height fields over East Antarctica prior to and during the event. Ship observations are taken from a weather station aboard the $\mathrm{R} / \mathrm{V}$ Italica, which records all of the standard variables at 1-min intervals. Data from the $\mathrm{R} / \mathrm{V}$ Italica are extremely important to this analysis, especially as they coincide with critical events occurring offshore, which may not have been captured otherwise. Other ships are also in the Ross Sea during this time, but their position is either out of the study area, or generally close to Ross Island, which already has an extensive observational network. On the regional scale, satellite imagery is obtained from receiving stations at McMurdo and the Italian base at TNB, and processed using the Terascan software package. This includes Advanced Very High Resolution Radiometer
(AVHRR) digital imagery from the High Resolution Picture Transmission (HRPT) data stream broadcast by the suite of National Oceanic and Atmospheric Administration (NOAA) polar-orbiting satellites (1-km resolution at nadir), as well as Operational Line Scanner (OLS) data from the Defense Meteorological Satellite Program (DMSP) polar-orbiting constellation (0.6- and $2.7-\mathrm{km}$ resolution). Composite infrared imagery from SSEC ( $\sim 10 \mathrm{~km}$ resolution) is used to view synopticscale events in the Southern Hemisphere for latitudes higher than about $40^{\circ} \mathrm{S}$ (Stearns and Lazzara 1999).

Two noteworthy adjustments are made to the surface data. First, the station pressure at Schwerdtfeger AWS $\left(79.90^{\circ} \mathrm{S}, 169.97^{\circ} \mathrm{E}\right)$ on the Ross Ice Shelf is modified. Its sea level pressure (SLP) is systematically too low in relation to surrounding sites, but it displays the same temporal variations. In this study, the SLP values at Schwerdtfeger AWS are determined by adding $4 \mathrm{hPa}$ to the calculated SLP, and agree well with nearby AWS sites. Second, SLP from the Italica is taken as station pressure plus $2.5 \mathrm{hPa}$, an adjustment made necessary due to uncertainty in the instrument height above the ocean surface. This value $(2.5 \mathrm{hPa})$ is the average difference between the ship's station pressure and sea level pressure reduced from Eneide AWS $\left(74.70^{\circ} \mathrm{S}\right.$, $\left.164.10^{\circ} \mathrm{E}\right)$, near the Italian base at TNB, while the ship was docked there from 0200 UTC 15 January through 1200 UTC 16 January. The elevation at Eneide is near sea level $(90 \mathrm{~m})$, and known to be accurate.

The upper-level analysis makes use of National Centers for Environmental Prediction-National Center for Atmospheric Research reanalysis (NNR) model output (Kalnay et al. 1996), as well as rawinsonde data from McMurdo station and the Italian base at TNB. NNR $2.5^{\circ}$ $\times 2.5^{\circ}$ gridded output for geopotential height at the 500$\mathrm{hPa}$ level is used to determine the location and intensity of upper-level support in the region. These data are validated and slightly adjusted using point data from rawinsondes at McMurdo and TNB, and by estimating 500-hPa geopotential heights from surface data at AWS and AGO sites at high $(>2300 \mathrm{~m})$ East Antarctic locations using a regression method developed by Phillpot (1991). This method uses the hypsometric equation to estimate the thickness of the layer between the surface (where the given station is located) and the 500-hPa level for an air column with a mean virtual temperature (MVT) of $0^{\circ} \mathrm{C}$. A temperature correction is then applied to reflect the departure of the layer-observed MVT from $0^{\circ} \mathrm{C}$, based on a regression relationship obtained from radiosonde observations during the International Geophysical Year. The corrected layer thickness is added to the station elevation to obtain the 500-hPa geopotential height.

It is noteworthy that Phillpot's method is only applicable at relatively high elevations, as the error increases with increasing thickness of the surface-to-500$\mathrm{hPa}$ layer. Phillpot estimates the standard deviation at $3500 \mathrm{~m}$ to be $\sim 17 \mathrm{gpm}$, increasing to $\sim 25 \mathrm{gpm}$ at 2400 
$\mathrm{m}$, and does not recommend the procedure for stations below $2400 \mathrm{~m}$. Here, we use one station with an elevation that is below $2400 \mathrm{~m}$ (AGO site $\mathrm{P} 6,69.50^{\circ} \mathrm{S}$, $\left.130.02^{\circ} \mathrm{E}\right)$. However, there is some uncertainty, as Augsburg University gives the elevation of site P6 as 2343 $\mathrm{m}$, while the SSEC gives an elevation of $2530 \mathrm{~m}$. (We use Augsburg University's elevation values for the AGO stations, as they maintain the sites.) This problem of determining accurate station elevations is frequently encountered at remote locations, as most elevation measurements are taken from aircraft altimeter. To minimize the error caused by uncertainty in the elevation measurements, for the period 10-17 January we take the average difference of the Phillpot-derived 500-hPa geopotential heights and the NNR 500-hPa geopotential heights (interpolated to the coordinates of each station), and then add this value to the Phillpot-derived 500-hPa geopotential heights. The adjusted Phillpot-derived 500$\mathrm{hPa}$ values are remarkably similar to the NNR values, and serve to validate the NNR 500-hPa fields for use in this analysis. The adjusted Phillpot-derived 500-hPa fields tend to place the 500 -hPa center slightly farther north than the NNR fields, which is in agreement with the upper-level winds observed in the McMurdo and TNB rawinsonde observations (presented later).

The NNR sea level pressure field is not used in this study. In contrast to the $500-\mathrm{hPa}$ field, in which terrain features are absent, this field does not have the spatial resolution required to resolve the complex mountainous terrain in the western Ross Sea region. This is apparent when comparing the NNR sea level pressure field (not shown) with surface observations and satellite imagery, which do not agree well. Because of the uncertainty of the NNR sea level pressure field, we do not use the lowlevel NNR vertical motion fields.

Midtropospheric NNR vertical velocity fields are used to relate the location of upper-level features to surface low pressure centers in the absence of reliable NNR sea level pressure fields. These data indicate areas of upward (downward) air motion associated with the likely areas of formation of low (high) pressure. We use 500-hPa vertical velocities in this text because of the general reliability of the NNR fields at this level. The vertical velocity patterns at $500 \mathrm{hPa}$ are similar to levels closer to the surface, and can be observed in the 700-, 850-, and 925-hPa NNR fields (not shown).

\section{Event analysis}

\section{a. Northerly low $\left(L_{N}\right)$}

Figure $2 \mathrm{a}$ is a manual analysis of available surface observations superimposed on a satellite image for 1700 UTC 13 January. The sea level pressure on the R/V Italica (indicated by the "ship" label) is 5-6 hPa lower than the AWS sites in and around TNB, implying the pressure decreases to the east (seaward) from Victoria Land. Strong southerly winds on the ship and at Ales- sandra AWS (the coastal site farthest north of TNB in Fig. 2a) imply clockwise flow around a depression $\left(\mathrm{L}_{\mathrm{N}}\right)$ to the east. At this time, $\mathrm{L}_{\mathrm{N}}$ (track shown in Fig. 1) is to the northeast of TNB, with an intensity of approximately $994 \mathrm{hPa}$.

At 0600 UTC 14 January (Fig. 2b), winds on the R/ $\mathrm{V}$ Italica shift to the southwest, indicating $\mathrm{L}_{\mathrm{N}}$ has moved to the southeast of the ship, and weakened to $996 \mathrm{hPa}$. This is the first time in the satellite imagery that a cloud signature is associated with this depression, as indicated by a faint hook (wisp) under the $\mathrm{L}_{\mathrm{N}}$ symbol. Prior to this time, upper-level clouds prevented detection of $\mathrm{L}_{\mathrm{N}}$. Also note the darkened region in TNB and over the Drygalski Ice Tongue (not present in Fig. 2a), a thermal signature indicating katabatic outflow from David, Reeves, and Priestley Glaciers (e.g., Bromwich 1989b). A smaller depression, just inland of TNB, forms at this time. The feature remains in the same region throughout the event, and its stationary nature suggests an association with the katabatic outflow. This area of low pressure is discussed in greater detail in section $3 \mathrm{~d}$.

At 2000 UTC 14 January (Fig. 2c), $\mathrm{L}_{\mathrm{N}}$ begins to reintensify as it nears Ross Island. This intensification is likely supported by the katabatic outflow from TNB, as well as the onset of merging with the more prominent system to the southeast of Ross Island $\left(\mathrm{L}_{\mathrm{S}}\right)$. At this time, the cloud hook associated with $\mathrm{L}_{\mathrm{N}}$ becomes more noticeable, and a clear area to the east of TNB indicates the seaward propagation of the katabatic winds (evidenced by 34-kt winds observed aboard the R/V Italica), which appear to be contributing to the organization of a frontal boundary at the low and middle levels.

At 0700 UTC 15 January (Fig. 2d), a well-organized cyclone is centered to the southeast of Ross Island. It is difficult to identify large-scale rotation before this time, as there is a (daily occurring) time gap from approximately 2000 to 0300 UTC in the satellite imagery. Although the presence of $\mathrm{L}_{\mathrm{N}}$ (and probably several other depressions) can still be distinguished from $\mathrm{L}_{\mathrm{S}}$ in the AWS wind/pressure fields, the satellite image clearly indicates one main area of rotation, with $\mathrm{L}_{\mathrm{S}}$ being the most prominent. After 0700 UTC 15 January, $\mathrm{L}_{\mathrm{N}}$ cannot be identified as a distinct entity in the surface or satellite observations, and we assume it has merged with $\mathrm{L}_{\mathrm{S}}$.

\section{b. Southerly low $\left(L_{S}\right)$}

Concurrently, another depression, $\mathrm{L}_{\mathrm{S}}$, is emerging from East Antarctica immediately to the west of Ross Island. The first indication is a trough in the $1000-\mathrm{hPa}$ isobar to the west of Ross Island at 1700 UTC 13 January (Fig. 2a). Northerly surface winds near McMurdo, and a subtle decrease in SLP from Ross Island toward the coast provide further evidence of this system. Upperlevel support for this system is found in the NNR 500$\mathrm{hPa}$ geopotential height field at 1800 UTC 13 January (Fig. 3a), which resolves a depression over East Antarctica to the west of Ross Island. 
(a)

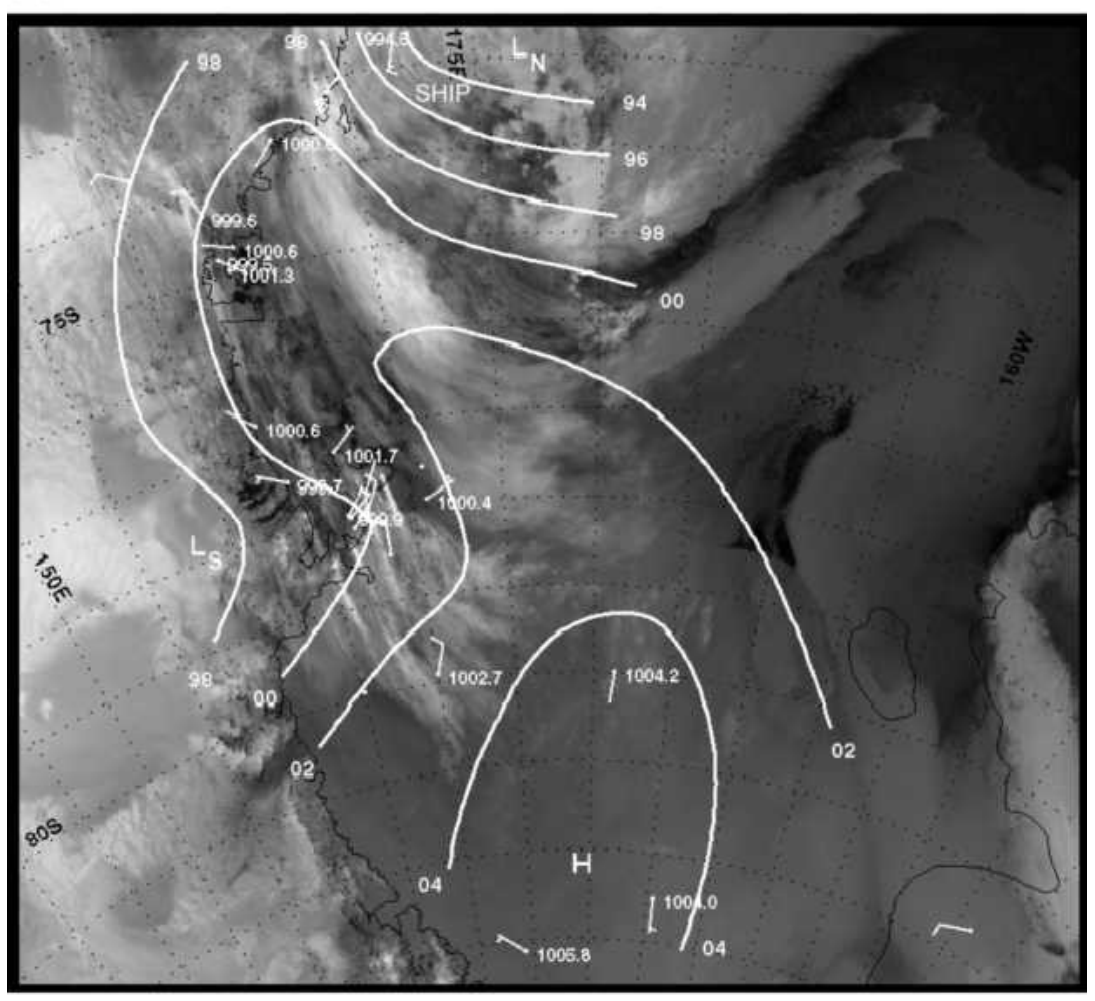

(b)

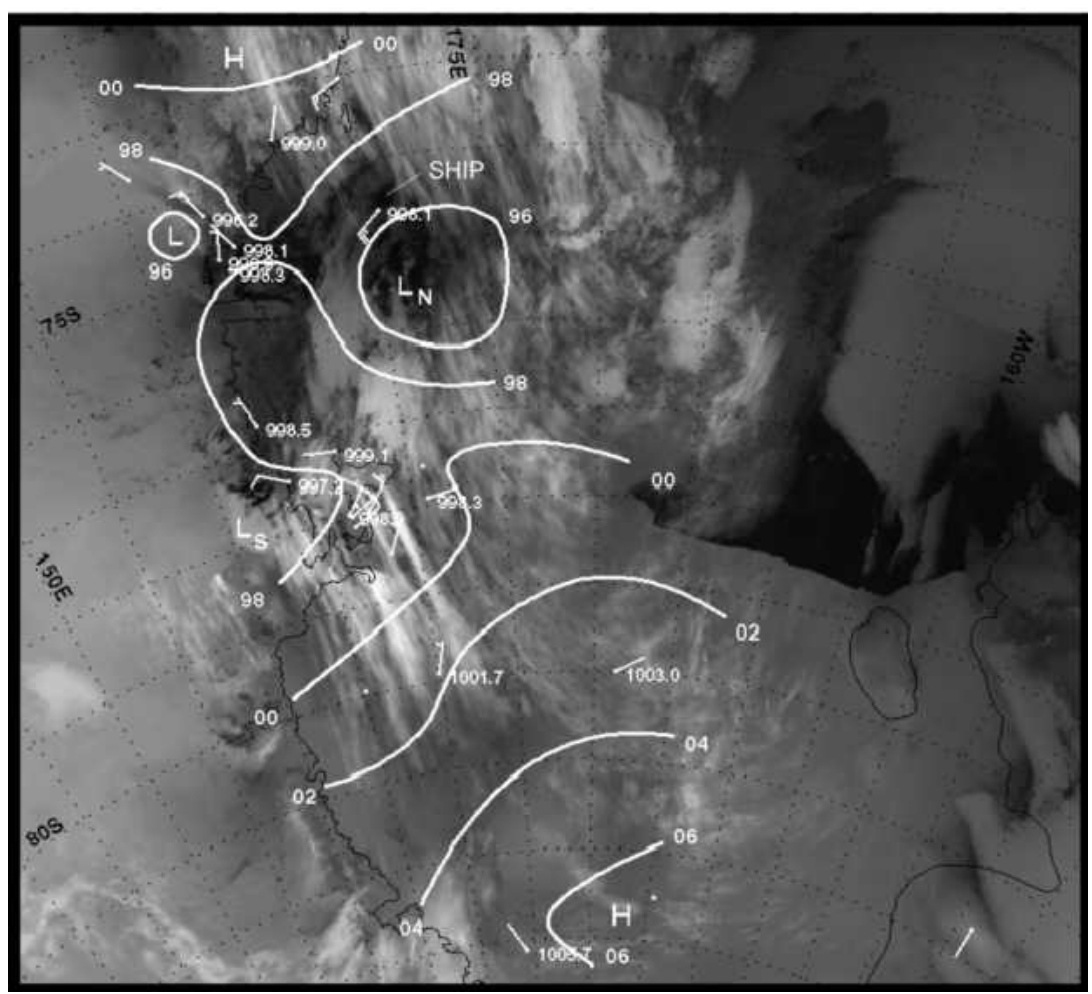

FIG. 2. (a) Satellite imagery indicating conditions in the Ross Sea region, 1700 UTC 13 Jan 2001. AWS observations of SLP and surface wind vectors are from 1800 UTC. Isobars 
(c)

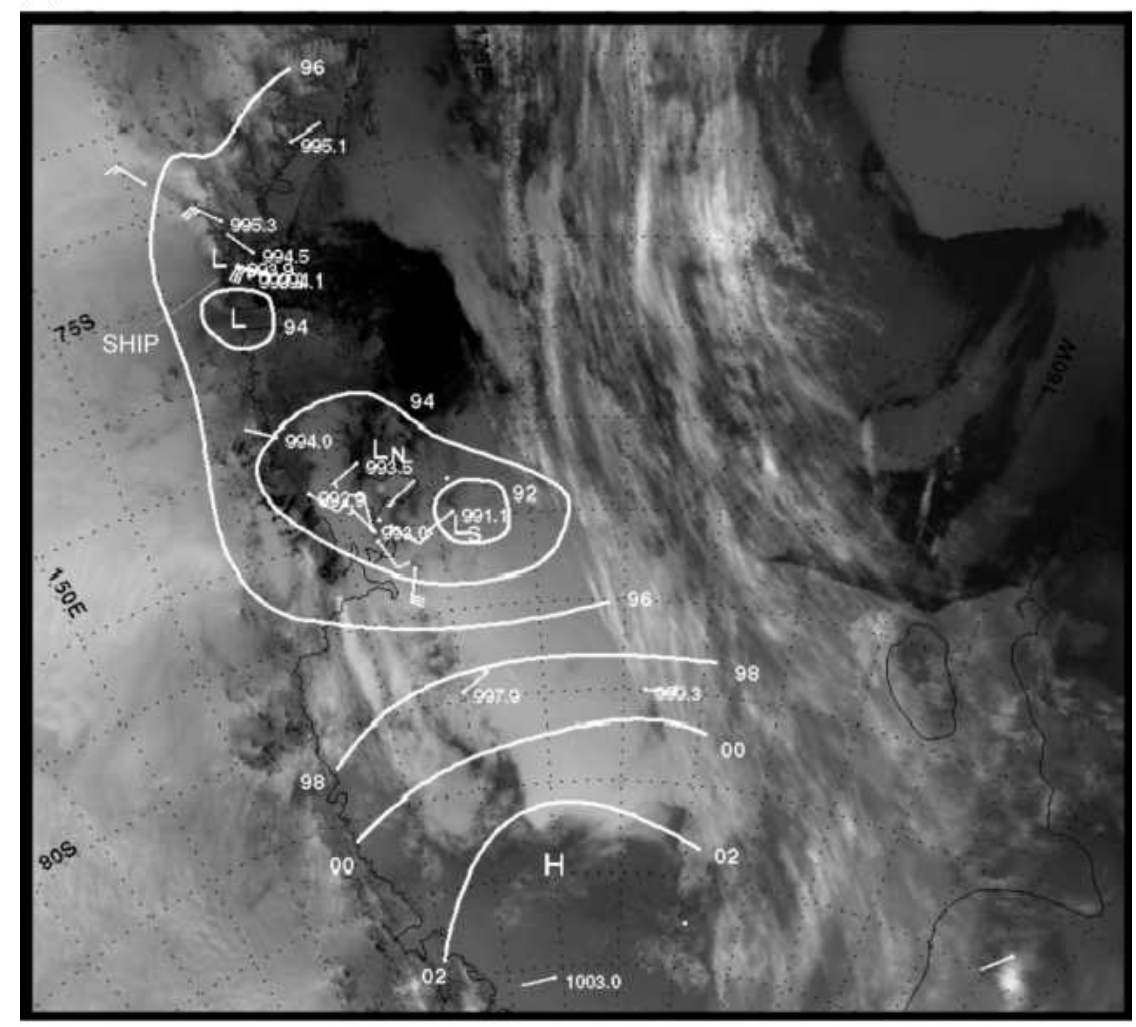

(d)

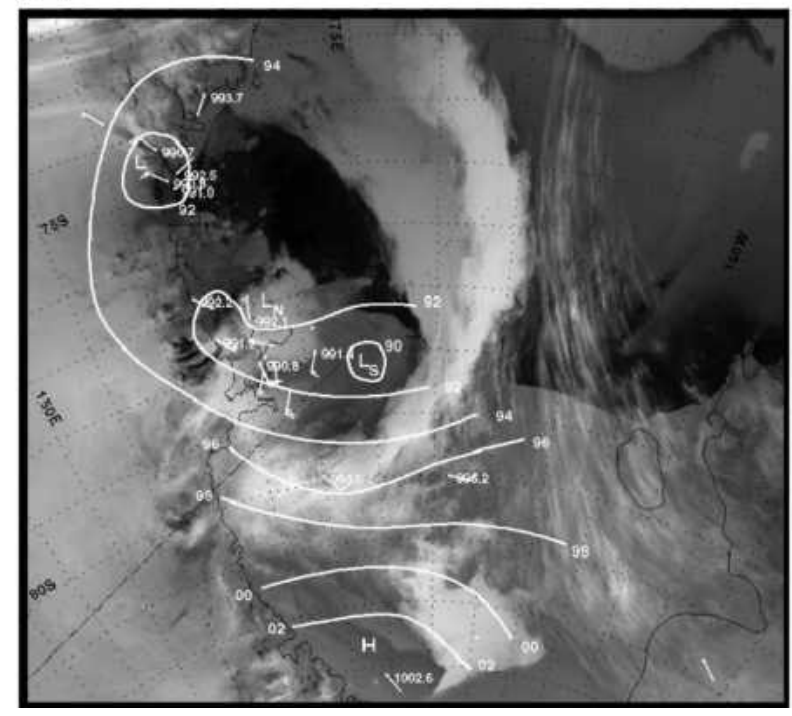

FIG. 2. (Continued) represent SLP in $\mathrm{hPa}(92=992 \mathrm{hPa}, 02=1002 \mathrm{hPa})$. Wind speed is measured in kt. (a), (c) The DMSP OLS infrared channel (10-12 $\mu \mathrm{m})$. (b), (d) The NOAA AVHRR infrared channel $4(10.3-11.3 \mu \mathrm{m})$. (b) Same as in (a) but for 0600 UTC 14 Jan. AWS observations are also from 0600 UTC. (c) Same as in (a) but for 2000 UTC 14 Jan. AWS observations are from 2100 UTC. (d) Same as in (a) but for 0700 UTC 15 Jan. AWS observations are from 0600 UTC. 
(a)

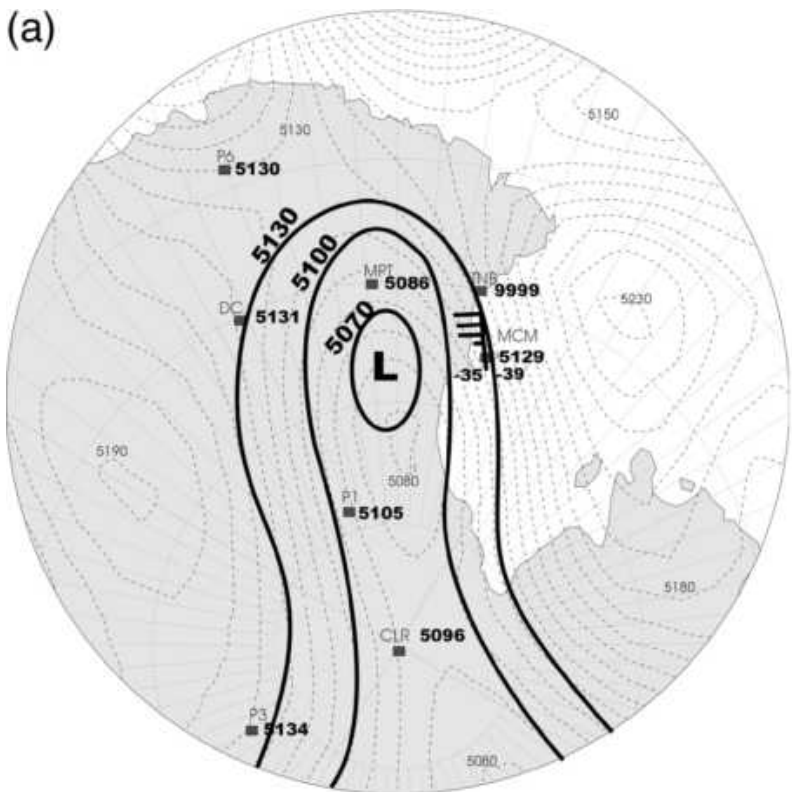

(c)

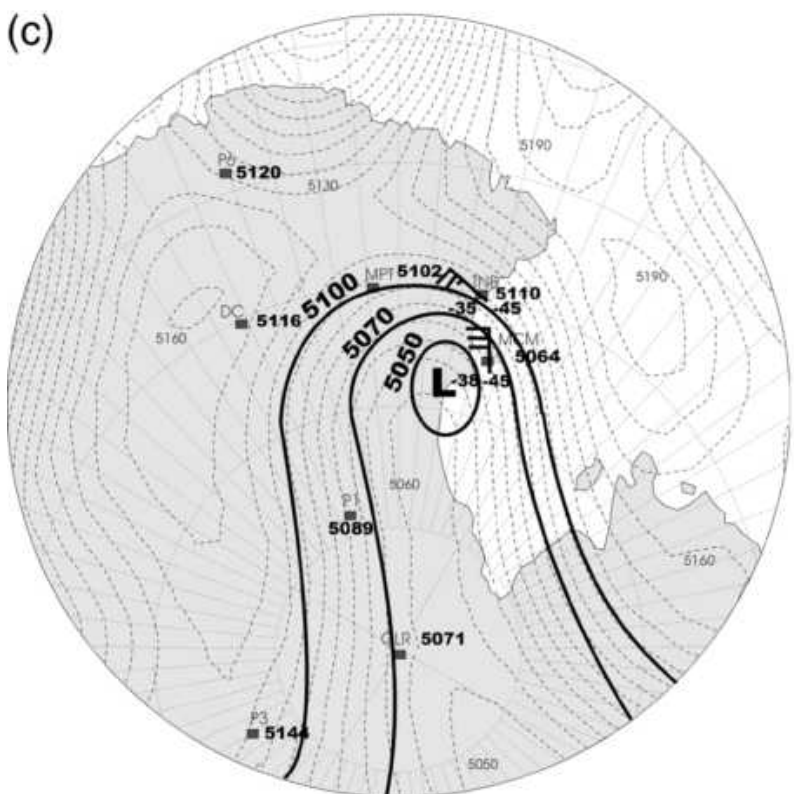

(b)

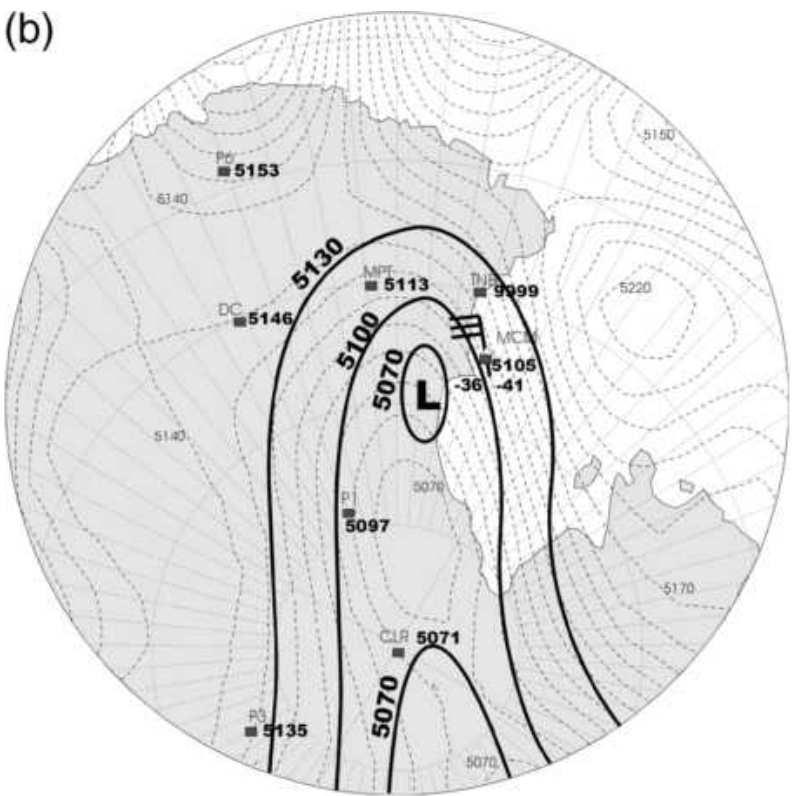

(d)

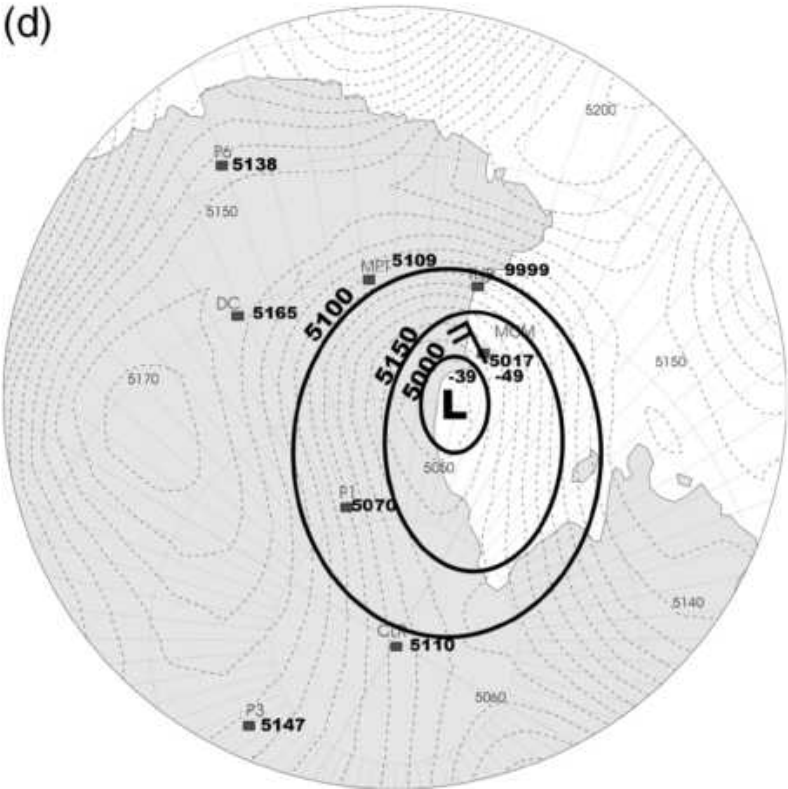

FIG. 3. (a) The 500-hPa geopotential heights (gpm) at 1800 UTC 13 Jan 2001. Dashed lines are the NNR values (shown in small print). Bold lines indicate the adjusted placement of the 500-hPa low, based on point values extrapolated from surface stations [AGO sites P1, P3, P6; AWS sites Dome C II (DC); Midpoint (MPT); and Clean Air (CLR)] and rawinsondes at McMurdo (MCM) and Terra Nova Bay (TNB), using the method of Phillpot (1991). No data available is represented by 9999 . Geopotential height (gpm, upper right), temperature $\left(\mathrm{C}^{\circ}\right.$, lower left), and dewpoint ( $\mathrm{C}^{\circ}$, lower right) are listed at the rawinsonde sites, and are interpolated in time. Estimated 500-hPa geopotential heights are given for the AGO and AWS sites. (b) Same as in (a) but for 0600 UTC 14 Jan. (c) Same as in (a) but for 1800 UTC 14 Jan. (d) Same as in (a) but for 0600 UTC 15 Jan.

At 0600 UTC 14 January (Fig. 2b) $\mathrm{L}_{\mathrm{S}}$ can be clearly resolved for the first time, indicated by a $\sim 2 \mathrm{hPa}$ fall in the AWS pressure fields near McMurdo and continued northerly winds. No cloud signature is associated with the system at this time. Upper-level support continues as the NNR 500-hPa depression moves eastward, closer to Ross Island (Fig. 3b, 0600 UTC 14 January). This is reflected in the McMurdo rawinsonde observations by a $\sim 25$ gpm drop in geopotential height [note that the 500-hPa geopotential heights, winds, and temperatures shown in Figs. 3a-d over McMurdo and TNB are interpolated from the actual rawinsonde observations taken (not the NNR fields) at 0000 and 1200 UTC each day, shown in Table 1].

Fourteen hours later, at 2000 UTC 14 January (Fig. 2c), $\mathrm{L}_{\mathrm{s}}$ has intensified by $\sim 6 \mathrm{hPa}$ to $991 \mathrm{hPa}$, and moved 
TABLE 1. The 500-hPa data for 13-16 Jan 2001.

\begin{tabular}{|c|c|c|c|c|c|c|c|c|c|c|c|c|}
\hline \multirow{2}{*}{$\begin{array}{c}\text { Time and } \\
\text { date source }\end{array}$} & \multicolumn{4}{|c|}{1200 UTC 13 Jan } & \multicolumn{4}{|c|}{0000 UTC 14 Jan } & \multicolumn{4}{|c|}{1200 UTC 14 Jan } \\
\hline & $\mathrm{McM}$ & NCEP & TNB & NCEP & $\mathrm{McM}$ & NCEP & TNB & NCEP & $\mathrm{McM}$ & NCEP & TNB & NCEP \\
\hline GPM & 5130 & 5135 & $\mathrm{n} / \mathrm{a}$ & 5161 & 5127 & 5126 & $\mathrm{n} / \mathrm{a}$ & 5151 & 5082 & 5093 & 5118 & 5118 \\
\hline $\mathrm{T}$ & -35 & -34 & $\mathrm{n} / \mathrm{a}$ & -35 & -35 & -36 & $\mathrm{n} / \mathrm{a}$ & -36 & -37 & -37 & -36 & -36 \\
\hline RH & 72 & 64 & $\mathrm{n} / \mathrm{a}$ & 46 & 70 & 19 & $\mathrm{n} / \mathrm{a}$ & 32 & 63 & 50 & 48 & 53 \\
\hline WD & 344 & 333 & $\mathrm{n} / \mathrm{a}$ & 340 & 349 & 323 & $\mathrm{n} / \mathrm{a}$ & 334 & 343 & 337 & 333 & 321 \\
\hline WS & 37 & 26 & $\mathrm{n} / \mathrm{a}$ & 27 & 34 & 27 & $\mathrm{n} / \mathrm{a}$ & 23 & 30 & 21 & 13 & 16 \\
\hline \multirow{2}{*}{$\begin{array}{c}\text { Time and } \\
\text { date source }\end{array}$} & \multicolumn{4}{|c|}{0000 UTC 15 Jan } & \multicolumn{4}{|c|}{1200 UTC 15 Jan } & \multicolumn{4}{|c|}{0000 UTC 16 Jan } \\
\hline & $\mathrm{McM}$ & NCEP & TNB & NCEP & $\mathrm{McM}$ & NCEP & TNB & NCEP & $\mathrm{McM}$ & NCEP & $\mathrm{TNB}$ & NCEP \\
\hline GPM & $5039 *$ & 5060 & 5102 & 5099 & 4994 & 5034 & $\mathrm{n} / \mathrm{a}$ & 5091 & 5015 & 5042 & $\mathrm{n} / \mathrm{a}$ & 5103 \\
\hline $\mathrm{T}$ & -38 & -37 & -33 & -35 & -40 & -37 & $\mathrm{n} / \mathrm{a}$ & -34 & -41 & -38 & $\mathrm{n} / \mathrm{a}$ & -34 \\
\hline RH & 34 & 25 & 25 & 27 & 33 & 19 & $\mathrm{n} / \mathrm{a}$ & 4 & 39 & 22 & $\mathrm{n} / \mathrm{a}$ & 35 \\
\hline WD & 348 & 331 & 285 & 295 & 318 & 301 & $\mathrm{n} / \mathrm{a}$ & 279 & 256 & 274 & $\mathrm{n} / \mathrm{a}$ & 290 \\
\hline WS & 30 & 21 & 15 & 21 & 17 & 11 & $\mathrm{n} / \mathrm{a}$ & 26 & 7 & 14 & $\mathrm{n} / \mathrm{a}$ & 25 \\
\hline
\end{tabular}

$\mathrm{McM}=$ McMurdo station rawinsonde, $\mathrm{TNB}=$ Terra Nova Bay rawinsonde, NCEP $=$ NCEP-NCAR reanalysis interpolated to the same point as the respective rawinsonde, GPM $=$ geopotential meters, $\mathrm{T}=$ temperature $\left({ }^{\circ} \mathrm{C}\right), \mathrm{RH}=$ relative humidity $(\%)$, WD $=$ wind direction $\left({ }^{\circ}\right.$ from geographic $\left.\mathrm{N}\right)$, WS $=$ wind speed $(\mathrm{kt})$.

* Estimated.

just east of Ross Island. Note that winds near McMurdo, in general, have shifted $180^{\circ}$, now blowing from the south. This is indicative of clockwise flow around a low centered to the east. The first cloud signature associated with the depression appears at this time, as indicated by a crescent-shaped front extending from the north of TNB and wrapping southward around $\mathrm{L}_{\mathrm{S}}$. Upper-level support for $\mathrm{L}_{\mathrm{S}}$ continues as the NNR 500-hPa depression moves northeast toward Ross Island (Fig. 3c, 1800 UTC 14 January), evidenced by a decrease in geopotential height of 40 gpm over McMurdo (interpolated from rawinsonde observations).

At 0700 UTC 15 January (Fig. 2d), the center of $\mathrm{L}_{\mathrm{S}}$ has moved to the southeast of Ross Island. However, it continues to intensify $(990 \mathrm{hPa})$ as the upper-level support moves eastward. The NNR 500-hPa depression intensifies by $\sim 50$ gpm (Fig. 3d, 0600 UTC 15 January). This is reflected in the interpolated rawinsonde values over McMurdo, which drop by $47 \mathrm{gpm}$ for the period. The satellite cloud signature in Fig. 2d also clearly indicates the center of $\mathrm{L}_{\mathrm{S}}$ lying to the southeast of Ross Island, with a large hook surrounding the $\mathrm{L}_{\mathrm{S}}$ symbol. After 0600 UTC on 15 January, the surface low continues to track southeast under the leading edge of the $500-\mathrm{hPa}$ depression. The southeast movement of this upper-level depression is indicated in the McMurdo rawinsonde data by the shift in wind direction from northwest to west (clockwise around the low) between 0000 UTC 15 January and 0000 UTC 16 January (Table 1). The storm continues to track southeastward across the Ross Ice Shelf (Fig. 1) and eventually dies out as it encounters West Antarctica, probably as a result of losing upper-level support.

\section{c. Further support for the existence of $L_{S}$}

Much effort is spent in this study verifying the existence of $\mathrm{L}_{\mathrm{S}}$. This is necessary, as the features of $\mathrm{L}_{\mathrm{S}}$ are difficult to resolve over the data-sparse region of East Antarctica and not readily evident in the satellite data while the system is in its early stages (before $\sim 0100$ UTC 15 January). Furthermore, the existence of $\mathrm{L}_{\mathrm{S}}$ with respect to the performance of the Polar MM5 is critical, as the model does not resolve this feature until it is a well-developed cyclone to the southeast of Ross Island (discussed later). Figures 4a (1800 UTC 14 January) and 4b (0600 UTC 15 January) are intended to relate the upper-level conditions, for which we have a reasonable amount of evidence, to the surface conditions. The areas of upward vertical velocity shown in these two sequences indicate probable regions of upper-level support for surface cyclone formation and intensification. The vertical velocity field at the $500-\mathrm{hPa}$ level is representative of vertical velocity fields at levels closer to the surface (discussed in the section on data). Inspection of Fig. 4a reveals that the placement of the upward velocity feature associated with $\mathrm{L}_{\mathrm{S}}$ (indicated by the U) is too far south. However, as shown in Fig. $3 \mathrm{c}$ (for the same time), our Phillpot analysis resolves a $500-\mathrm{hPa}$ depression farther to the north and east of the NNR feature, which corresponds well with the interpolated rawinsonde observations from McMurdo and TNB. Had the upper-level low-pressure center been resolved correctly in the NNR 500-hPa geopotential height field, placing it farther to the northeast, the vertical velocity field shown in Fig. 4a would also be placed farther to the northeast, providing evidence of upward air movement associated with $\mathrm{L}_{\mathrm{S}}$ (the location of $\mathrm{L}_{\mathrm{S}}$ at this time is shown in Fig. 1). In Fig. 4b (and subsequent sequences, not shown), the upward air motion corresponds well with the placement of $\mathrm{L}_{\mathrm{S}}$, indicating the correct placement of the upper-level support in the NNR 500-hPa geopotential height field. This is in agreement with the Phillpot analysis and interpolated rawinsonde data for McMurdo and TNB (Fig. 3d). 
(a)

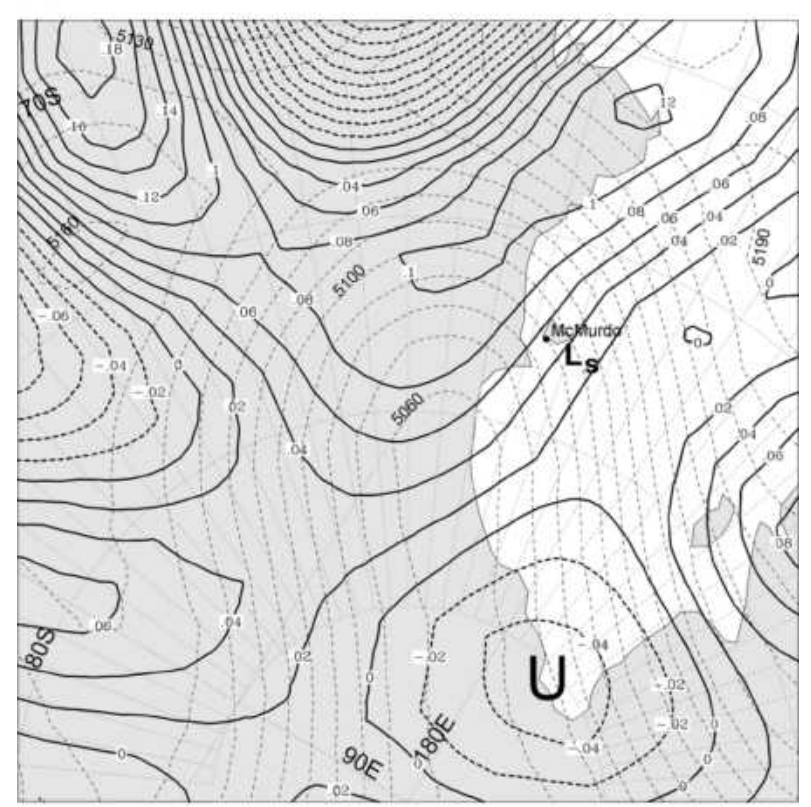

(b)

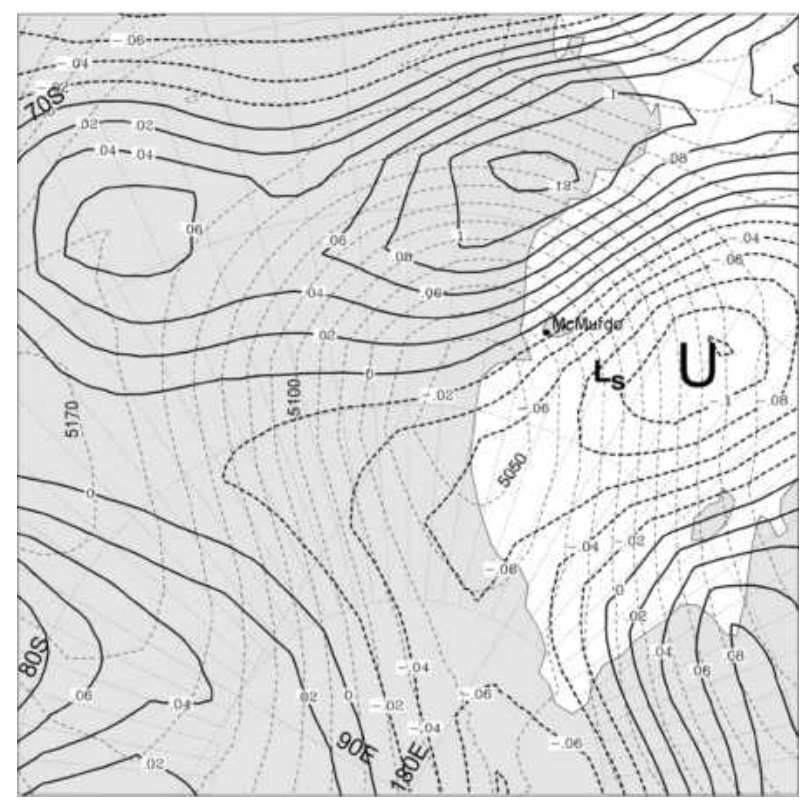

FIG. 4. (a) NNR 500-hPa vertical motion $\left(\mathrm{Pa} \mathrm{s}^{-1}\right)$ superimposed on the NNR 500-hPa geopotential height (gpm, light dashed), 1800 UTC 14 Jan 2001. Negative values in the vertical motion field indicate upward air velocity. The $U$ indicates a center of upward velocity. The surface position of the surface low, $\mathrm{L}_{\mathrm{S}}$, is also shown. (b) Same as in (a) but for 0600 UTC 15 Jan.

The intensity of the upward vertical motion is also of interest. There is a significant increase in upward vertical velocity at the center of the $U$ feature from Fig. $4 \mathrm{a}$ to Fig. 4b, tripling in magnitude from -0.4 to -1.2 $\mathrm{Pa} \mathrm{s}^{-1}$, respectively. This coincides with the extensive development of $\mathrm{L}_{\mathrm{S}}$ between these two time periods, as observed in Figs. 2c and 2d.

\section{d. Katabatic wind event}

A katabatic event during the period of cyclogenesis is suggested in the wind speed and direction observations at Zoraida AWS $\left(74.25^{\circ} \mathrm{S}, 163.17^{\circ} \mathrm{E}\right)$, on the Priestley Glacier near TNB (Fig. 5). A significant increase in wind speed ( $\sim 25 \mathrm{kt})$ begins at 1200 UTC 13 January and continues through 1200 UTC 16 January. Throughout the event, the wind direction stays nearly constant toward the southeast (i.e., from the northwest), down the narrow valley in which the AWS is located. This is characteristic of the intense, consistent winds associated with a katabatic episode (e.g., Bromwich et al. 1993). In support of the observations at Zoraida AWS, the seaward propagation of the winds is reflected in the measurements aboard the R/V Italica as it travels toward TNB on 14 January (Fig. 6). Note the increase in offshore wind intensity as the ship nears the entrance to the bay. At 1800 UTC, the winds are nearly $40 \mathrm{kt}$. Unfortunately, the anemometer at Inexpressible Island (Manuela) AWS $\left(74.95^{\circ} \mathrm{S}, 163.69^{\circ} \mathrm{E}\right)$ is not operational for this period of study. The wind measurements at Inexpressible Island are a reflection of the outflow from Reeves Glacier and are commonly used as an indicator of katabatic wind intensity and duration in TNB (e.g., Bromwich 1989a).

During the Antarctic summer katabatic winds are less frequent, and the onset of a katabatic event generally requires some form of synoptic forcing (Bromwich et al. 1993). Rather than cyclogenesis as a result of katabatic forcing, an existing cyclone or synoptic disturbance may trigger a katabatic event (which, in turn, can fuel new or existing systems). Therefore, it is worth considering that an existing depression initializes the katabatic surge.

Carrasco and Bromwich (1995) investigate a similar weather event, in which a midtropospheric disturbance exists in southern Victoria Land to the southwest of TNB and moves eastward. The authors suggest that the cyclonic circulation associated with this low pressure center $\left(\mathrm{L}_{\mathrm{S}}\right.$ in their text, resolved at the 500-hPa level) supports a katabatic event observed at Reeves Glacier, which acquires a northwesterly direction. Similarly, the upper-level trough indicated over East Antarctica (Figs. 3a-d) may be responsible for the katabatic winds observed in the surface and satellite data during the study period (Toniazzo 1994). Support for this is suggested by the upper-level winds observed in the TNB rawinsonde data, which are northwest and west-northwest at 1200 UTC 14 January and 0000 UTC 15 January, respectively (Table 1). Unfortunately, there is a gap in the TNB rawinsonde data after this time. However, the winds observed in the McMurdo rawinsonde become west-southwest by 0000 UTC 16 January, indicating the 


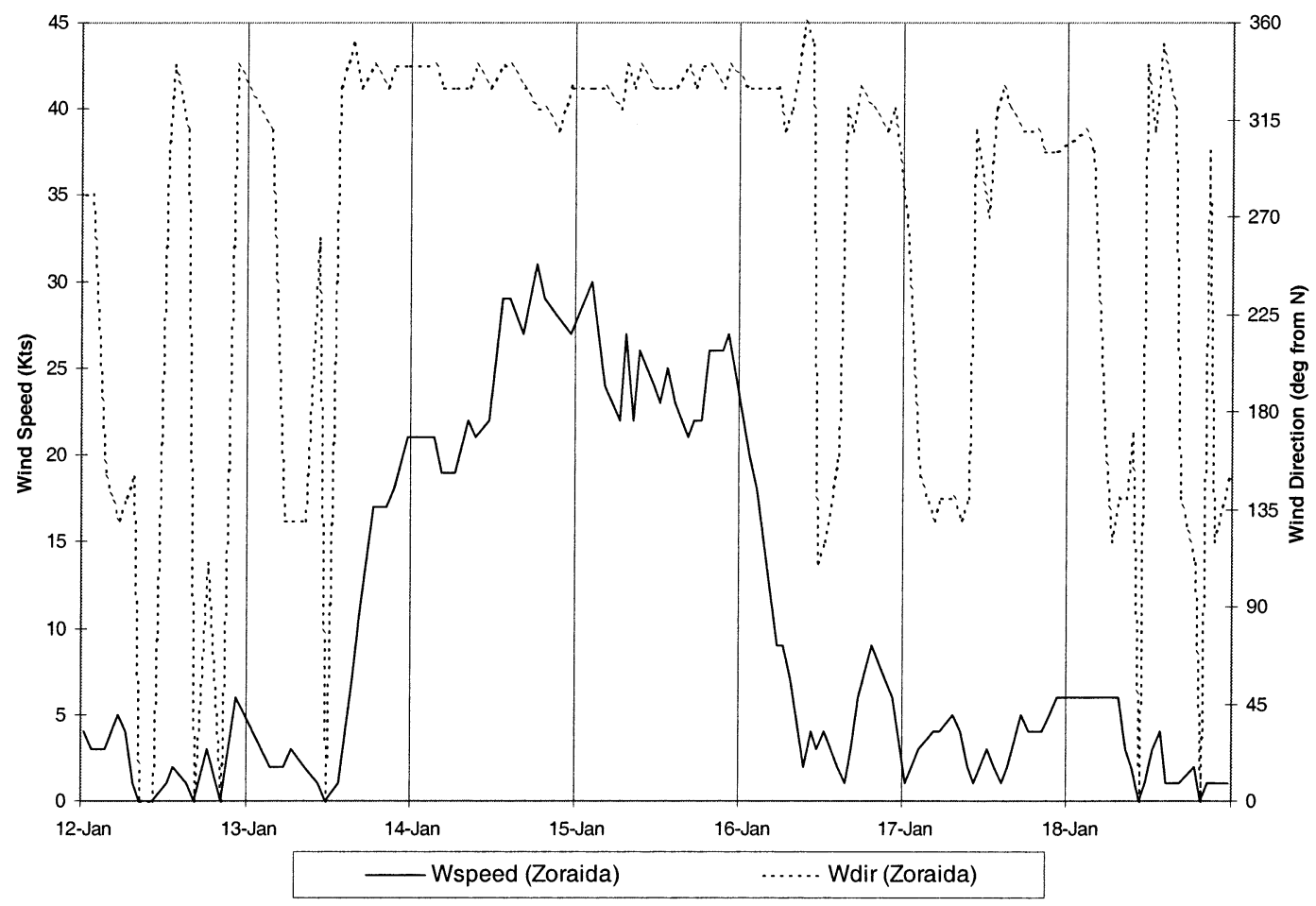

FIG. 5. Wind speed (kt) and direction $\left({ }^{\circ}\right.$ from N) at Zoraida AWS on the Priestley Glacier near TNB, 12-18 Jan 2001.

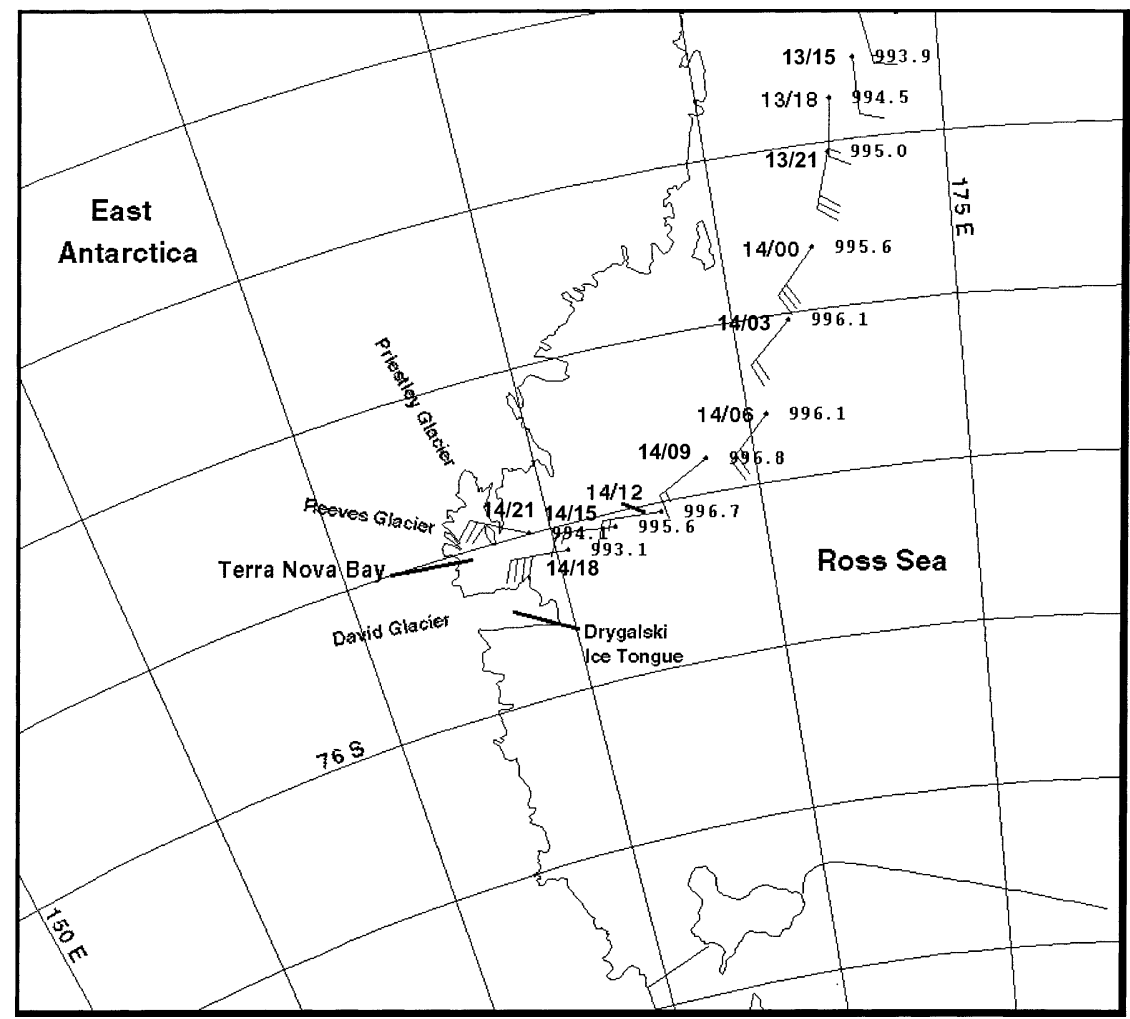

FIG. 6. Track of the R/V Italica, showing wind speed (kt) and direction, and SLP (hPa), 13-14 Jan 2001; 13/18 = 1800 UTC 13 Jan. 
system has moved to the east of Ross Island (and TNB). The winds subside soon after, by 1200 UTC 16 January.

Figure 1 shows two low pressure areas in the vicinity of TNB. Both depressions show up in the AWS pressure fields on 14 January, soon after the winds intensify at Priestley Glacier (Fig. 5), and a prominent thermal (dark) signature appears in the satellite imagery (Figs. $2 \mathrm{~b}-\mathrm{d})$, representing katabatic drainage from the glaciers near TNB (Bromwich 1989b). They remain relatively stationary throughout the event and merge around 0300 UTC 15 January. While the cause of this general area of low pressure is in question, the timing suggests a relationship to the katabatic winds draining into TNB. Carrasco and Bromwich (1995) note a similar low pressure area in their study, forming during a katabatic outbreak (shown in Figs. 8d-f of their paper). They conjecture the strong, continental winds may have provided cold air for the creation of a baroclinic zone near TNB, ideal for cyclogenesis.

On a larger scale, the katabatic event appears responsible for the frontogenesis accompanying the development of $\mathrm{L}_{\mathrm{S}}$, seen in Figs. $2 \mathrm{c}$ and $2 \mathrm{~d}$ as a prominent band of middle- and upper-level clouds extending from north of TNB to the southeast of Ross Island, with very clear conditions extending seaward from TNB. Carrasco and Bromwich (1995) give a model of frontogenesis in relation to katabatic events at TNB (see their Figs. 11a and 11b). Briefly, the cold air from TNB spirals into an existing cyclone $\left(\mathrm{L}_{\mathrm{S}}\right.$ in this case) from the north, causing the relatively warm maritime air over the Ross Sea to ascend (this would be associated with formation of the prominent cloud band). In their example, the center of the low is to the north of the Ross Ice Shelf, whereas in this study, $\mathrm{L}_{\mathrm{S}}$ is centered over the Ross Ice Shelf. However, the intensity of the system suggests the influence of its circulation extends well to the north of the Ross Ice Shelf.

\section{e. Barrier wind event}

Barrier wind events occur when cyclones present over the western Ross Ice Shelf and Ross Sea direct stable low-level easterly airflow toward the Transantarctic Mountains. The barrier wind regime is set up when the flow is blocked and turned northward parallel to the mountain range by a pressure gradient normal to the mountains (O'Connor et al. 1994), occurring about 7\% of the time during a 2-yr study period. Strong southerly winds are associated with these events. O'Connor et al. (1994) define a barrier wind event in the western Ross Sea as 1) having a cyclone (mesoscale or synoptic scale) to the east or northeast, 2) having surface isobars at a large angle to the Transantarctic Mountains in the Byrd Glacier and Minna Bluff regions, and 3) having wind speeds stronger than the monthly average and wind directions normal to the isobars as observed at AWS sites deployed in the area.

Figures $7 \mathrm{a}$ and $7 \mathrm{~b}$ depict the conditions in the Ross
Island region before and during the barrier wind event, respectively. In Fig. 7a (0600 UTC 14 January), note that the low pressure center is still to the west of Ross Island. Isobars south of Minna Bluff are nearly parallel to the Transantarctic Mountains, and winds are generally from the north. These conditions do not meet the criteria for a barrier wind event. However, the eastward movement of the low pressure center indicates that winds will soon shift. Twenty-four hours later (Fig. 7b, 0600 UTC 15 January), the low pressure system has moved east of Ross Island (criterion 1), and the wind at Schwerdtfeger AWS is now toward the Transantarctic Mountains from the southeast. The isobars have also migrated, now nearly perpendicular to the mountains (criterion 2). The wind at Linda AWS has shifted nearly $180^{\circ}$ (southerly) and intensified to $25 \mathrm{kt}$ (about 3 times the average wind speed for January 2001), and is normal to the isobars (criterion 3).

The flow from barrier winds is primarily to the east of Ross Island, due to topographic constraints imposed by Minna Bluff and Mount Discovery (O'Connor et al. 1994). However, there is also flow around the west side of the island, which affects McMurdo station. Figures $8 \mathrm{a}$ and $8 \mathrm{~b}$ show the time series of wind speed and direction at Linda AWS (located southeast of Ross Island) and Marble Point AWS (west of Ross Island), respectively. In Fig. 8a, winds at Linda AWS shift to the southsouthwest $\left(\sim 200^{\circ}\right)$ and intensify at about 1500 UTC 14 January, indicating the onset of the barrier wind event (this is also the first time in the manual analysis in which the isobars are perpendicular to the mountains). This event continues until approximately 1800 UTC 15 January, when the winds begin to subside and the isobars are no longer perpendicular to the mountains as $\mathrm{L}_{\mathrm{S}}$ moves eastward. The southerly winds at Linda AWS do continue, however, as flow from $\mathrm{L}_{\mathrm{S}}$ is now parallel to the mountains. Figure $8 \mathrm{~b}$ shows a similar trend for Marble Point AWS, with winds becoming consistently southeast $\left(100^{\circ}-150^{\circ}\right)$ throughout the same period (there is little change in intensity, however). The southeast flow is associated with barrier winds flowing around Minna Bluff, with a portion channeling northwestward through McMurdo Sound.

This barrier wind event (and its forcing mechanisms) is relevant in the following discussion on weather conditions at Williams Field. It is closely related to the sequence of precipitation and is associated with a brief break in the snowfall.

\section{f. Weather at Williams Field}

Williams Field, located immediately east of McMurdo on the Ross Ice Shelf, is the primary airstrip for USAP operations at the base during mid to late summer. The two $\sim 3000 \mathrm{~m}$ runways can be landed on from either end, providing four possible approaches from $330^{\circ}$, $250^{\circ}, 150^{\circ}$, and $70^{\circ}$. The flight minimum conditions for the $330^{\circ}$ approach, which has an obstruction (Ross Is- 

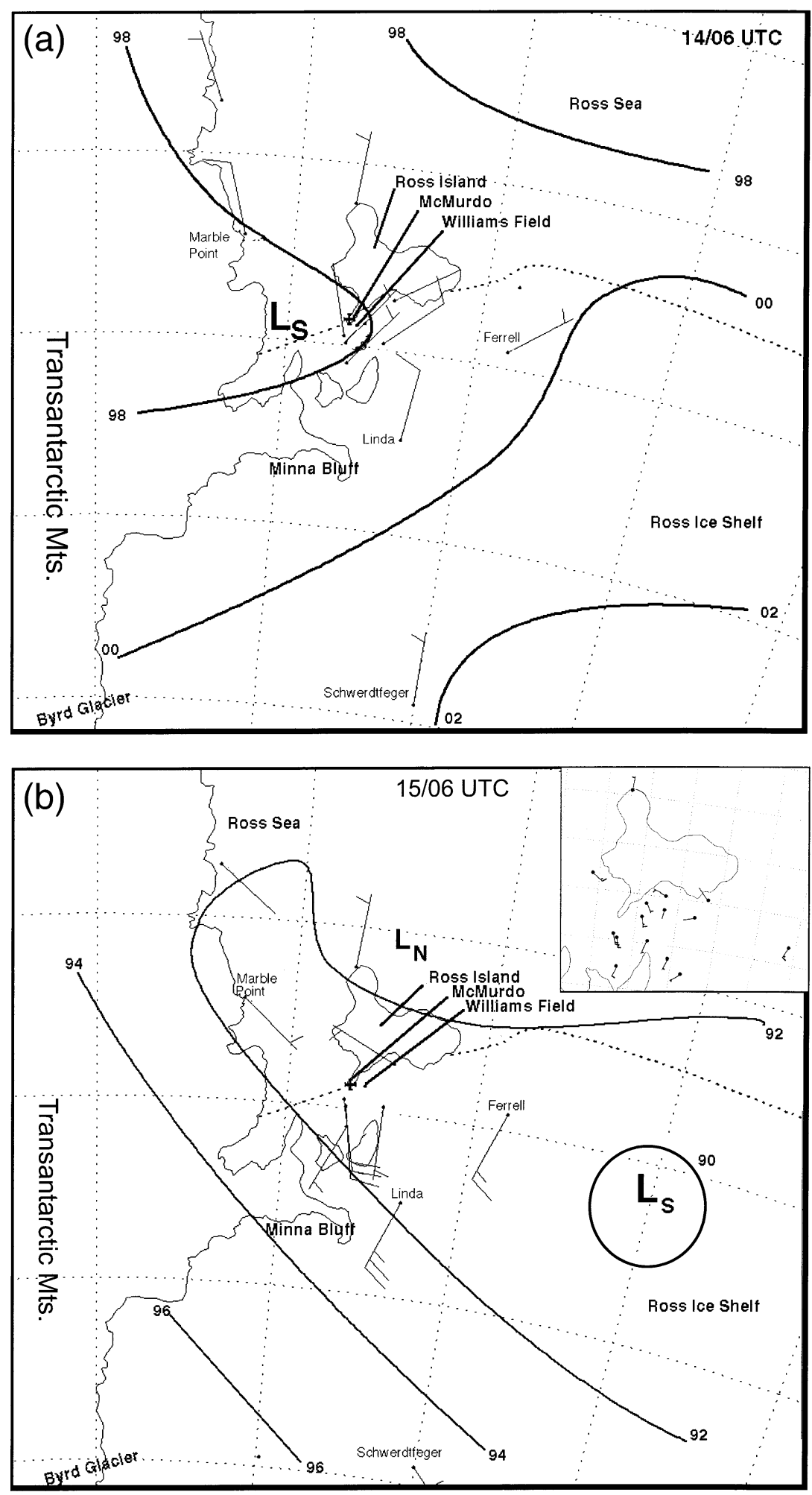

FIG. 7. (a) SLP (solid isobars in hPa; $92=992,02=1002$ ) near Ross Island at 0600 UTC 14 Jan 2001, just prior to the barrier wind event. Wind speed is measured in kt. Values listed next to the wind barbs are pressure anomalies (departure from Jan average; hPa) for the respective AWSs. (b) Same as in (a) but for 0600 UTC 15 Jan, during the barrier wind event. A detailed view of the surface winds near Ross Island is shown in the inset. 
(a)

Winds at Linda AWS

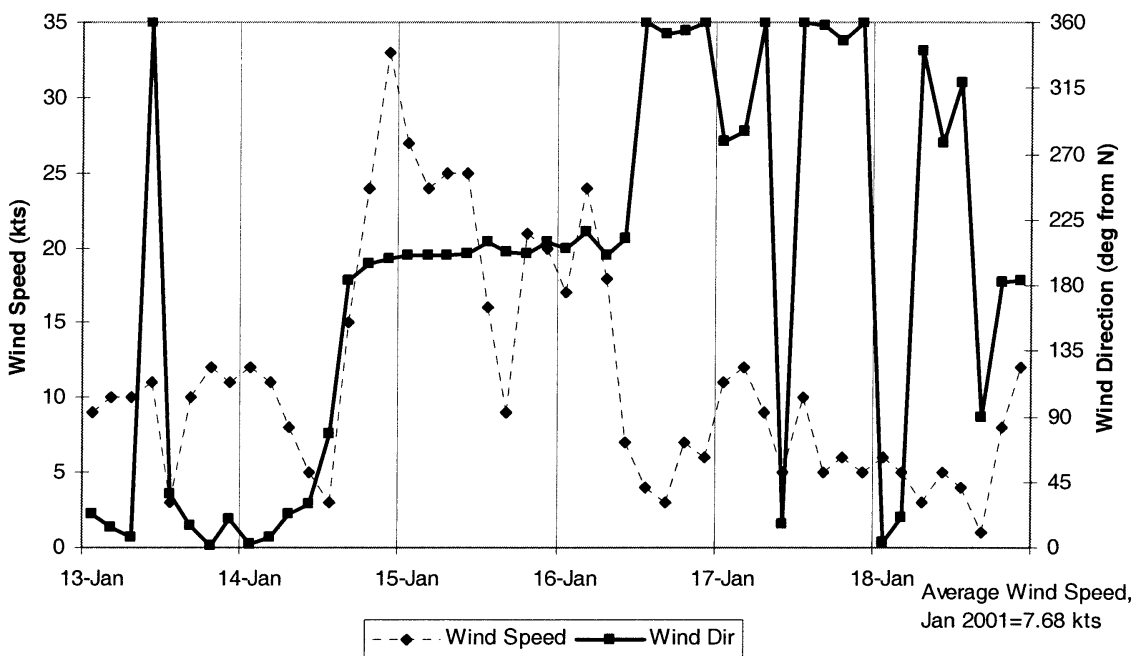

(b)

Winds at Marble Point AWS

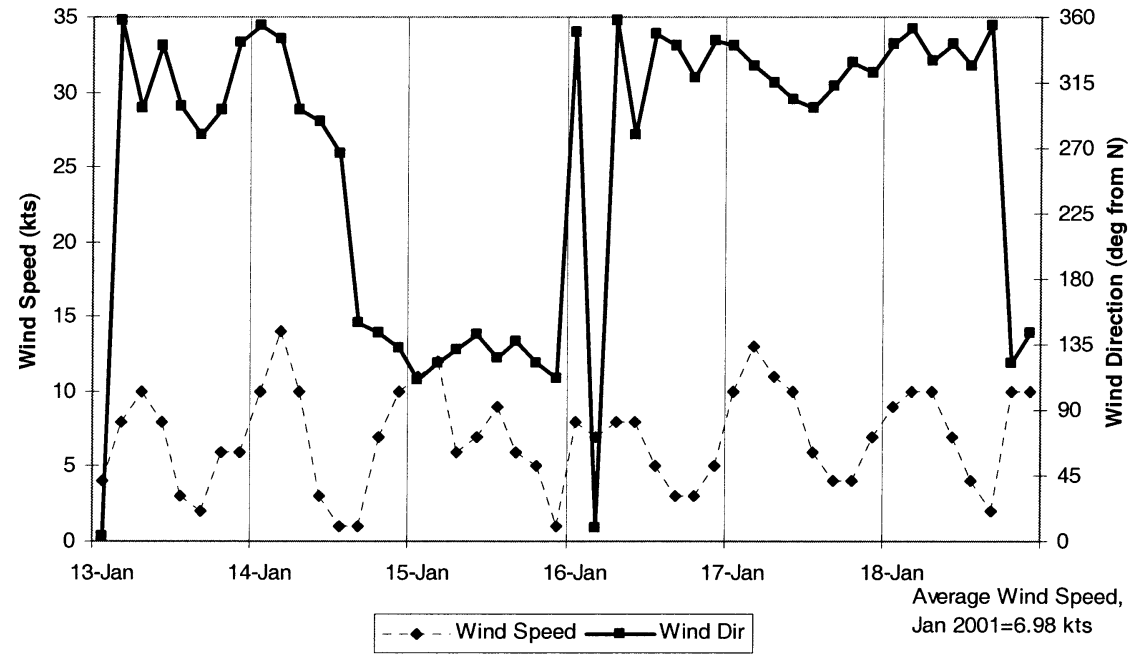

FIG. 8. Wind speed (kt) and direction $\left({ }^{\circ}\right.$ from $\mathrm{N}$ ) at (a) Linda AWS and (b) Marble Point AWS,

13-18 Jan 2001.

land), are 1600-m visibility with a $\sim 90 \mathrm{~m}$ ceiling. The other three approaches are less stringent, requiring $1200-\mathrm{m}$ visibility with a $\sim 60 \mathrm{~m}$ ceiling. Aviation forecasting is a primary task for meteorologists at McMurdo; hence, the weather conditions at the airfield are of principal forecasting concern during this event. Figures $9 \mathrm{a}$ and $9 \mathrm{~b}$ show time series plots of the wind speed, wind direction, visibility, and weather observations at Williams Field for 13-16 January 2001. The weather observations (shown along the top of Fig. 9b) indicate a few short snow events on 13 January and the first half of 14 January, but visibility is generally good $(>9000$ $\mathrm{m})$. Next, a snowfall of longer duration associated with low visibility begins at $\sim 1100$ UTC 14 January and lasts through $\sim 0400$ UTC 15 January $\left(\mathrm{W}_{\mathrm{X} 1}\right)$. During the latter part of $\mathrm{W}_{\mathrm{x} 1}$, and extending afterward (throughout most of 15 January), a period of strong winds associated with the barrier wind event occurs, causing drifting snow from $\sim 0600$ to 1500 UTC 15 January. Finally, another episode of snowfall and low visibility spans 1800 UTC 15 January through 0600 UTC 16 January $\left(\mathrm{W}_{\mathrm{X} 2}\right)$. On 16 January, visibility during $\mathrm{W}_{\mathrm{X} 2}$ periodically drops below flight minimum conditions.

\section{1) WeAther EVENT $W_{X 1}$}

The first precipitation/low visibility event, $\mathrm{W}_{\mathrm{X} 1}$, appears to be tied to $\mathrm{L}_{\mathrm{N}}$. At this time, the surface winds 

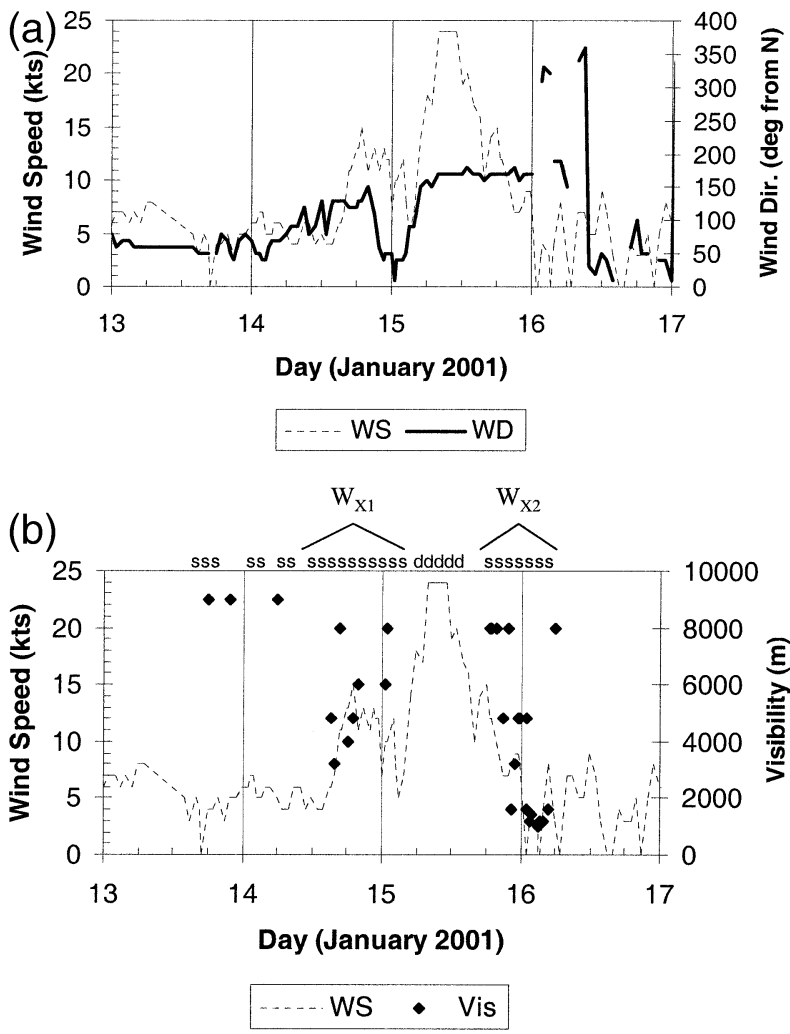

FIG. 9. (a), (b) Weather observations at Williams Field, 13-16 Jan 2001. Parameters are wind speed ( $\mathrm{kt})$, wind direction $\left({ }^{\circ}\right.$ from $\left.\mathrm{N}\right)$, and horizontal visibility $(\mathrm{m})$. At the top of $(\mathrm{b})$, note that $\mathrm{s}=$ snow and $\mathrm{d}=$ drifting snow. Visibility is not plotted if greater than $10 \mathrm{~km}$.

at Williams Field are most likely related to the beginning of the barrier wind event, flowing from the southeast (Fig. 9a), save for a brief window where the winds swing to the north from 2000 UTC 14 January to 0400 UTC 15 January (perhaps associated with a very small low pressure center not apparent at this resolution). However, in the satellite images at 0600 UTC 14 January (Fig. 2b-just prior to $\mathrm{W}_{\mathrm{X} 1}$ ) and 2000 UTC 14 January (Fig. 2c-during $\mathrm{W}_{\mathrm{X} 1}$ ), winds aloft are from the north, indicated by the white cloud streaks extending southward from the tops of the mountains in the vicinity. This is in agreement with the wind direction data from the McMurdo rawinsonde observations (Table 1), which indicate northerly winds throughout $\mathrm{W}_{\mathrm{X} 1}$. These winds are associated with the upper-level depression supporting $\mathrm{L}_{\mathrm{S}}$, which is nearing Ross Island (depicted in Fig. 3c, 1800 UTC 14 January). [Note that while the upper-level support for $\mathrm{L}_{\mathrm{S}}$ is nearing the island, $\mathrm{L}_{\mathrm{S}}$ (a surface feature) has passed to the south of Ross Island by 1200 UTC 14 January (Fig. 1) and is probably not associated with the snow observed during $\mathrm{W}_{\mathrm{X} 1}$.] Perhaps moist air is transported into the system as $\mathrm{L}_{\mathrm{N}}$ nears the north side of Ross Island, bringing a cloud mass with it. This is depicted in Fig. 2c, in which $\mathrm{L}_{\mathrm{N}}$ is placed just offshore from Cape Byrd, to the north of Ross Island (where it remains throughout $\mathrm{W}_{\mathrm{X} 1}$, probably stalled by the leeside low set up by the barrier wind event). The ascent of moist air associated with the low-level cyclonic rotation of $\mathrm{L}_{\mathrm{N}}$, in conjunction with northerly upper-level winds associated with $\mathrm{L}_{\mathrm{S}}$, is most likely responsible for the orographic lifting of moist air over Ross Island, contributing to the continuance of $\mathrm{W}_{\mathrm{X} 1}$ until 0400 UTC 15 January.

\section{2) WeAther EVENT $W_{X 2}$}

The second event, $\mathrm{W}_{\mathrm{X} 2}$, occurs after $\mathrm{L}_{\mathrm{N}}$ and $\mathrm{L}_{\mathrm{S}}$ have merged (after the two lows have merged the cyclone is referred to by its primary component, $\mathrm{L}_{\mathrm{S}}$ ) and a welldeveloped cyclone is present to the southeast of Ross Island (position indicated in Fig. 1). Event $\mathrm{W}_{\mathrm{X} 2}$ begins immediately following the barrier event (Fig. 9b), indicated by snow and low visibility starting at 1800 UTC 15 January. The lower-tropospheric winds, which had been normal to the Transantarctic Mountains near Byrd Glacier during the barrier wind event, are now flowing northward (parallel to the mountains) over Minna Bluff as $\mathrm{L}_{\mathrm{S}}$ moves southeastward. These winds are associated with the west (northward flowing) side of the cyclonic flow, and are most likely the cause of the precipitation observed at Williams Field during $\mathrm{W}_{\mathrm{X} 2}$. This is suggested in the satellite image in Fig. 10, which shows bright white clouds to the immediate north of Minna Bluff caused by orographic lifting of air over the topography. It is noteworthy that the image in Fig. 10 depicts the conditions at 0600 UTC 16 January, immediately following $\mathrm{W}_{\mathrm{X} 2}$, which are believed to be indicative of conditions during $\mathrm{W}_{\mathrm{X} 2}$. Images prior to this time are unavailable due to the daily occurring satellite time gap.

\section{3) WHY IS THERE NO SNOW BETWEEN $W_{\mathrm{X} 1}$ AND $\mathrm{W}_{\mathrm{X} 2}$ ?}

During a barrier wind event, much of the cyclonically forced flow that is normal to the mountains south of Minna Bluff is turned northward and flows around and over Minna Bluff, causing clouds and orographic snow on the lee (north) side (Fig. 11). Results from calculation of the barrier flow depth as a function of the Froude number (e.g., O'Connor and Bromwich 1988; Castro et al. 1983) indicate that a substantial portion of the barrier flow does pass over Minna Bluff. This is reinforced by inspection of rawinsonde observations at McMurdo, which show that a relatively deep southerly flow associated with the barrier wind event is observed near McMurdo, extending from the surface to approximately the $850-\mathrm{hPa}$ level ( $\sim 1200 \mathrm{~m}$ deep). It is conceivable that clouds and snowfall would be observed during this time, and in fact this does occur at the beginning of the barrier wind event, during $\mathrm{W}_{\mathrm{x} 1}$. However, during the peak of the barrier wind event on 15 January (the period between $\mathrm{W}_{\mathrm{X} 1}$ and $\mathrm{W}_{\mathrm{X} 2}$ ) no snowfall occurs. Examination of the rawinsonde ob- 


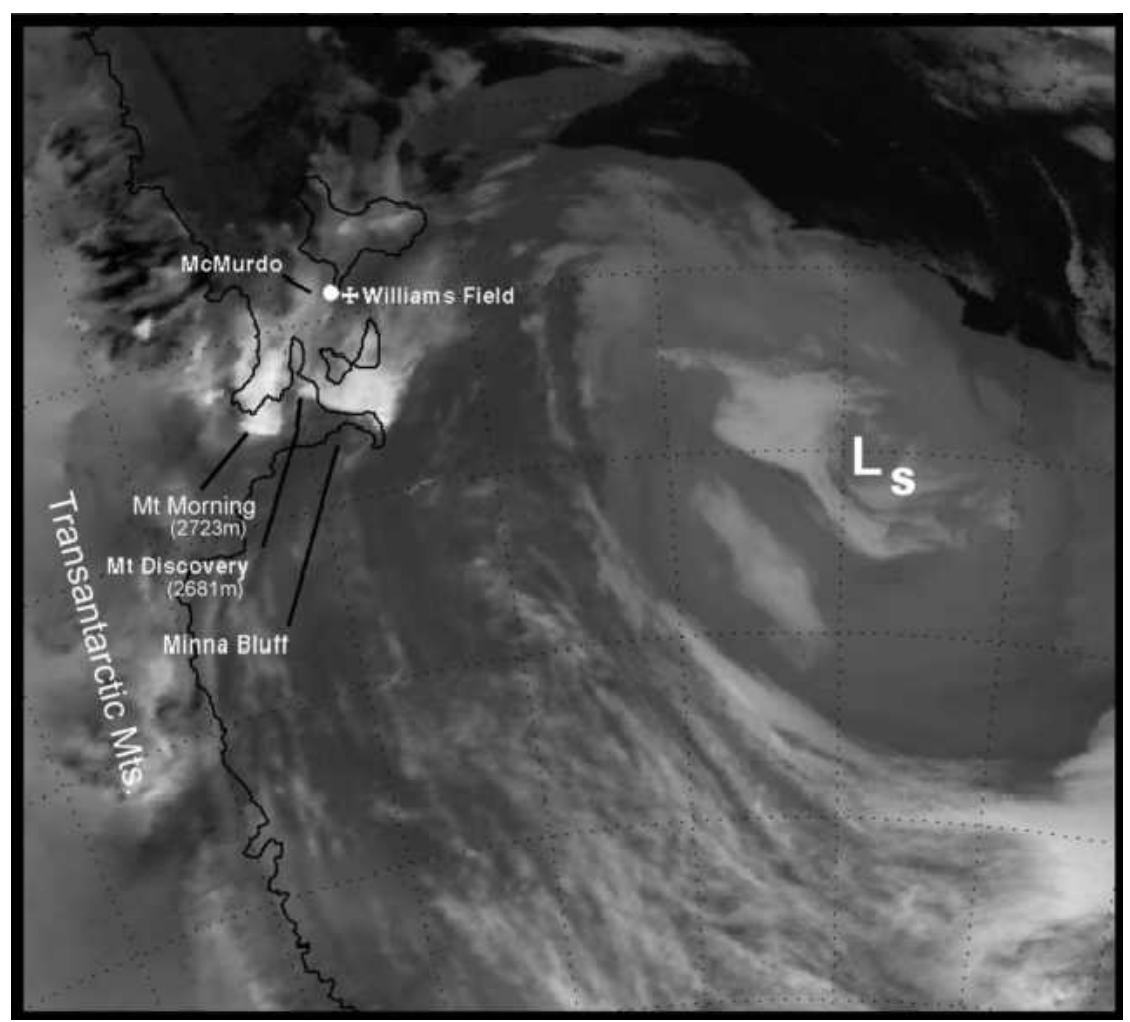

FIG. 10. State of the system at 0600 UTC 16 Jan 2001, immediately following $\mathrm{W}_{\mathrm{x} 2}$ at Williams Field. The white areas to the south of Ross Island are clouds resulting from orographic lifting over Minna Bluff as a result of the circulation represented by the $\mathrm{L}_{\mathrm{s}}$ to the east, and likely the cause of the snow and low visibility conditions observed at Williams Field during $\mathrm{W}_{\mathrm{X} 2}$. This image, which is the first available due to the satellite gap, is inferred to be representative of the conditions during $\mathrm{W}_{\mathrm{x} 2}$.

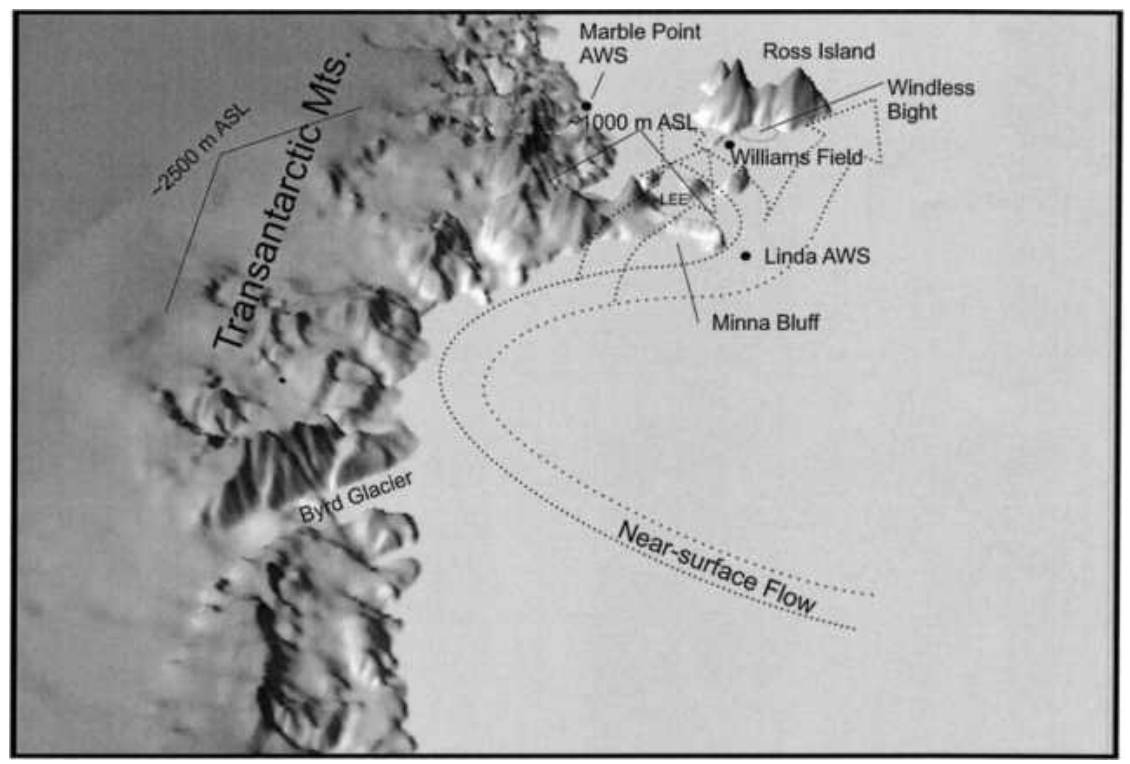

FIG. 11. Depiction of near-surface and lower-tropospheric flows during a cyclonically forced barrier wind event in the western Ross Sea/Ross Ice Shelf region. The terrain data are derived from the USGS GTOPO30 dataset. 


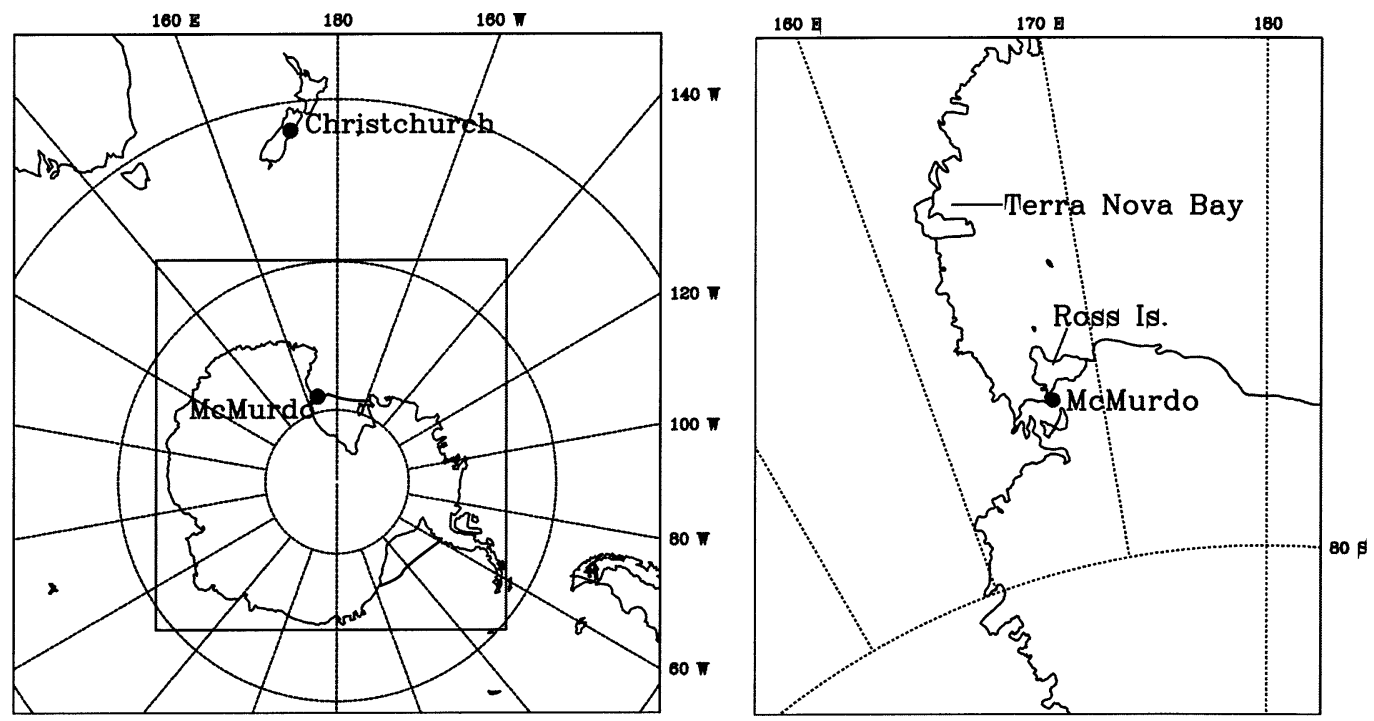

FIG. 12. AMPS MM5 domains: (a) 90- and 30-km grids and (b) 10-km grid.

servations from McMurdo and the surface data from Williams Field during this period indicate relatively low relative humidity values extending from the surface to approximately the $850-\mathrm{hPa}$ level. A more modest drop is also noted in the relative humidity fields at Linda AWS. This dry spell is the most likely reason for the break in precipitation between $\mathrm{W}_{\mathrm{X} 1}$ and $\mathrm{W}_{\mathrm{X}_{2}}$; however, it is not apparent as to why it occurs. It is conjectured that during barrier flow, cooler, drier winds are drawn out of the surrounding glacial valleys. There is also a shift in the winds aloft (at $700 \mathrm{hPa}$ ) from northerly during $\mathrm{W}_{\mathrm{X} 1}$ to westerly (from over the continental interior) during the break in precipitation, which may contribute to the lower relative humidity values observed. During the barrier wind event a modest drop in temperatures is noted in the rawinsonde records, and more markedly in the surface records. Subsequently, warming and increased relative humidity are observed after the barrier wind event, when the precipitation associated with $\mathrm{W}_{\mathrm{X} 2}$ occurs. There is also a deepening of the (generally) northward flowing air after the barrier wind event and during $\mathrm{W}_{\mathrm{X} 2}$, as $\mathrm{L}_{\mathrm{S}}$ moves eastward over the ice shelf. This deeper layer of air would be more favorable for cloud formation and precipitation on the lee side of Minna Bluff, as reduced subsidence would most likely occur near the top of the layer rather than near the surface (due to a dampening effect).

\section{Analysis of the Polar MM5}

\section{a. Description of the model}

The AMPS MM5 operates with three forecast domains, with horizontal grid spacings of 90, 30, and 10 km. The 90-km grid (Fig. 12a) covers most of the Southern Hemisphere poleward of $40^{\circ} \mathrm{S}$, including all of Ant- arctica and New Zealand. The $30 \mathrm{~km}$ grid (Fig. 12a) is designed to cover the whole Antarctic continent with mesoscale resolution. The $10-\mathrm{km}$ grid (Fig. 12b) covers the western Ross Sea with the highest resolution practicable and is centered on McMurdo. The forecast lengths are $48 \mathrm{~h}$ for the 90 - and 30-km grids, and $24 \mathrm{~h}$ for the $10-\mathrm{km}$ grid. The vertical resolution is 29 sigma levels between the ground and model top $(100 \mathrm{hPa})$. The initial and boundary conditions are derived from NCEP's global AVN model. The AVN first-guess field is objectively reanalyzed with a multiquadric technique (Nuss and Titley 1994) using those surface and upperair observations available in real time. Initialization times are at 0000 and 1200 UTC.

Several modifications have been made to the standard version of the MM5 in order to capture features unique to polar regions with extensive ice sheets, such as steep coastal margins and optimized snow characteristics. The Polar MM5 modifications include the following: (i) replacement of the Fletcher equation for ice nuclei concentration with that of Cooper (1986); (ii) in the CCM2 radiation scheme, representation of radiative properties of clouds as determined from the model's predicted microphysical species; (iii) use of the latent heat of sublimation for calculations of latent heat flux over ice surfaces and assumption of ice saturation when calculating surface saturation mixing ratios over ice; and (iv) accounting for a separate sea ice category with specified thermal properties (implemented after the 2000-01 field season). These modifications are discussed in greater detail (including references for the various parameterizations) in Bromwich et al. (2001) and Cassano et al. (2001), which are validation studies of the model performance over Greenland. Similarly, Guo et al. (2003) perform a validation study of the Polar MM5 in forecast mode over the Antarctic continent (60-km resolution). 


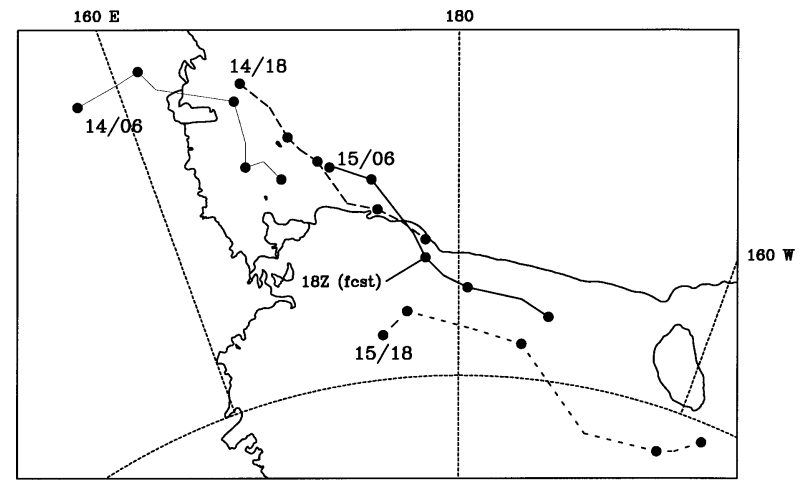

FIG. 13. Tracks of $10-\mathrm{km}$ AMPS low centers. The forecast tracks begin at 0600 and 1800 UTC 14 Jan and 0600 and 1800 UTC 15 Jan 2001. Beginning times of each forecast are indicated $(14 / 06=0600$ UTC 14 Jan), and dots mark positions every $6 \mathrm{~h}$. The 12 -h forecast low position from the 0600 UTC 15 Jan run (corresponding to 1800 UTC $15 \mathrm{Jan}$ ) is also marked. Positions of the $30-\mathrm{km}$ forecast low are used in the latter part of the tracks for the 15/06 and 15/18 UTC forecasts, where the low has left the $10-\mathrm{km}$ grid area.

\section{b. Analysis of AMPS forecasts}

The event under study spans 14-16 January 2001, and the AMPS forecasts of concern are those initialized at 0000 and 1200 UTC 14 and 15 January 2001. Each of these four runs simulate a cyclogenetic event in the western Ross Sea, with the later initializations moving the low farther to the south and east. Figure 13 presents the four $10-\mathrm{km}$ grid forecast tracks (solid) for the period, with the corresponding start times for that grid indicated (0600 UTC 14 January, 1800 UTC 14 January, 0600 UTC 15 January, 1800 UTC 15 January). Note that as the $10-\mathrm{km}$ grid is turned on at $6 \mathrm{~h}$ into the AMPS system forecast, the 24-h, $10-\mathrm{km}$ runs begin at the 6-h forecast (0600 and 1800 UTC).

In contrast to the observational analysis, AMPS developed only one low during this period. The initial signal for this appeared in the AVN-derived first-guess field at 0000 UTC 14 January on the continent west of TNB. This position is reflected in Fig. 13, for the 10$\mathrm{km}$ grid run starting at 0600 UTC 14 January. This run predicted an eastward movement of the center to TNB, where organization proceeded. The low then tracked generally southeastward through the subsequent runs.

Rather than distinctly reproducing the individual analyzed mesoscale lows, AMPS carries a single system. This model low is more consistent with $\mathrm{L}_{\mathrm{N}}$ through approximately 0600 UTC 15 January, and with $\mathrm{L}_{\mathrm{S}}$ thereafter. To examine this, Figs. 14a-e present SLP and surface winds from the $10-\mathrm{km}$ grid forecast initialized at 1200 UTC 14 January and beginning at hour 6, 1800 UTC 14 January. At this time (Fig. 14a), the 10-km grid places the SLP minimum east-northeast of TNB, while the circulation center is displaced from the pressure minimum and lies just east of the Drygalski Ice Tongue (located in Fig. 6). The central pressure is near $994 \mathrm{hPa}$. AMPS is simulating moderate $(24 \mathrm{kt})$ katabatic flow off the continent along the coast of TNB northward. This is verified by observations from Zoraida, which reports katabatic winds at this time of about $28 \mathrm{kt}$ (Fig. 5). This flow arises in response to the intensification of the offshore model low.

At the same time, the model reveals another katabatic zone south of Minna Bluff. This is associated with a low south of Minna Bluff, which reflects a trough that was present in the AVN first guess. It is unlikely this model low was actually present, as experience indicates that a local AWS, Schwerdtfeger, could have been reporting incorrect surface pressures (see above discussion in Section 2). Once in the GTS data stream, the reports could have been used by the AVN in its analysis for this time. This can only be conjectured, as the archived input data stream for the AVN is not readily available. In any event, this low is not related to $\mathrm{L}_{\mathrm{S}}$, which is much farther north at this time. No counterpart to $\mathrm{L}_{\mathrm{S}}$ south and east of Ross Island appears in the model output.

By 0000 UTC 15 January (10-km grid hour 12), the AMPS low has moved southeastward and deepened to $992 \mathrm{hPa}$. North of TNB, the katabatic flow has strengthened to $30 \mathrm{kt}$, which is supported by the Zoraida AWS observation for this time (Fig. 5). Although a trough extends southeastward from the low center over the ice shelf and overlaps the location of $\mathrm{L}_{\mathrm{S}}$ at this time, this is a coincidence, as $\mathrm{L}_{\mathrm{S}}$ has not been reproduced in the forecast.

At hour 18 (0600 UTC 15 January), the model low has moved east-southeast and deepened to $989 \mathrm{hPa}$ (Fig. 14c). A distinct trough extends south-southeastward over the ice shelf, although no separate center conforming to $\mathrm{L}_{\mathrm{S}}$ is reproduced. While katabatic flow continues north of TNB (in accordance with Zoraida AWS observations in Fig. 5), it is weakening in light of the offshore pressure rises (due to the departure of the model low) and a weakening east-west pressure gradient.

Of note at this time is the depression on the north side of Ross Island. This appears to be leeside low pressure in response to the strong southerly barrier wind flow over and around the island, and agrees with the timing of the observed barrier wind event, discussed in section 3e. This flow is not fully blocked; rather, a portion is going over Ross Island (this may be due in part to the horizontal resolution, which makes the model topography of Ross Island slightly less than it actually is). The model trough does coincide with the analyzed position of $\mathrm{L}_{\mathrm{N}}$ at this time, but in contrast with $\mathrm{L}_{\mathrm{N}}$ the model featured has developed in situ and has not been a distinct center that tracked to this position. The model counterpart to $\mathrm{L}_{\mathrm{N}}$ remains the main model center itself.

By hour 24 (1200 UTC 15 January), the 989-hPa low has reached the ice shelf (Fig. 14d), and is north of the analyzed position of $\mathrm{L}_{\mathrm{S}}$. The low in the wake (north) of Ross Island is now distinct. Closer examination (plots not shown) reveals a clear cyclonic circulation within it. In fact, a couplet of vortices exist: a dominant cy- 
(a)

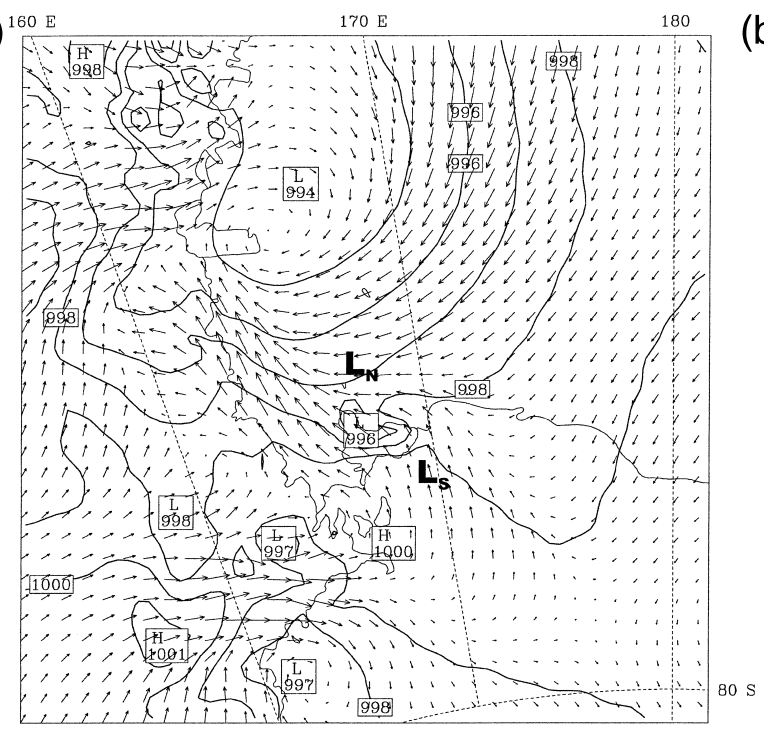

(c) ${ }^{16}$

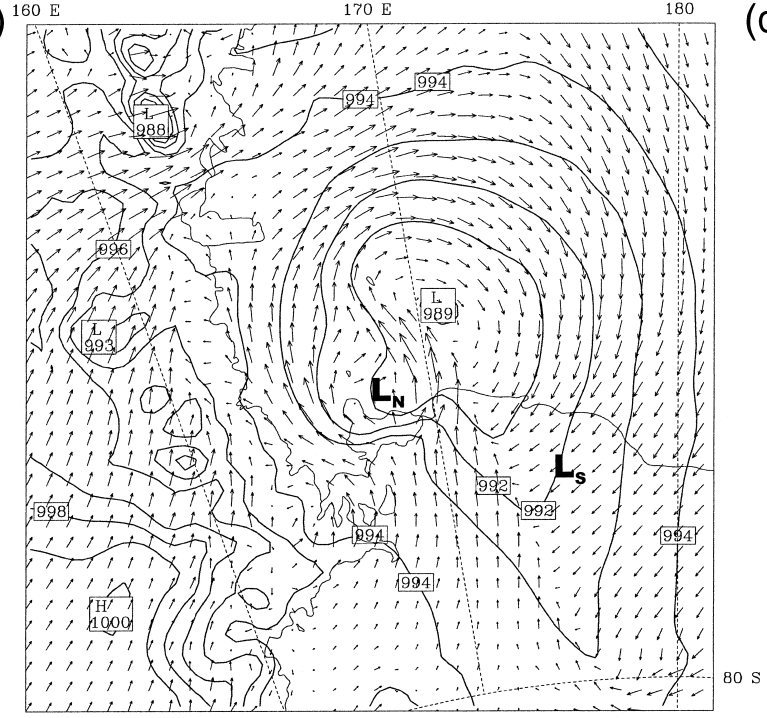

(b) ${ }^{100}$

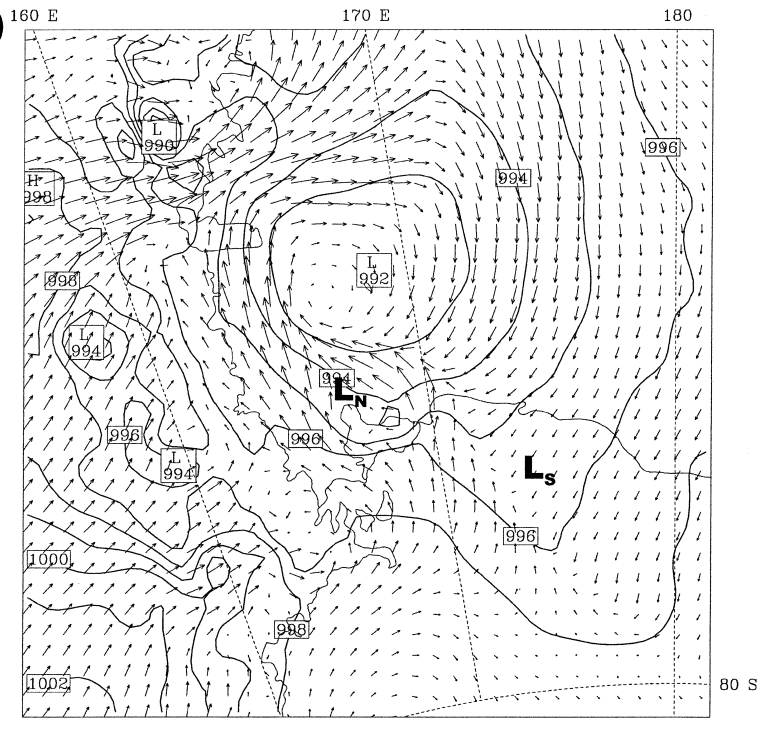

(d)

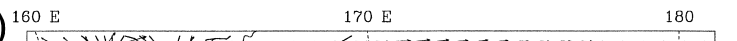

(e)

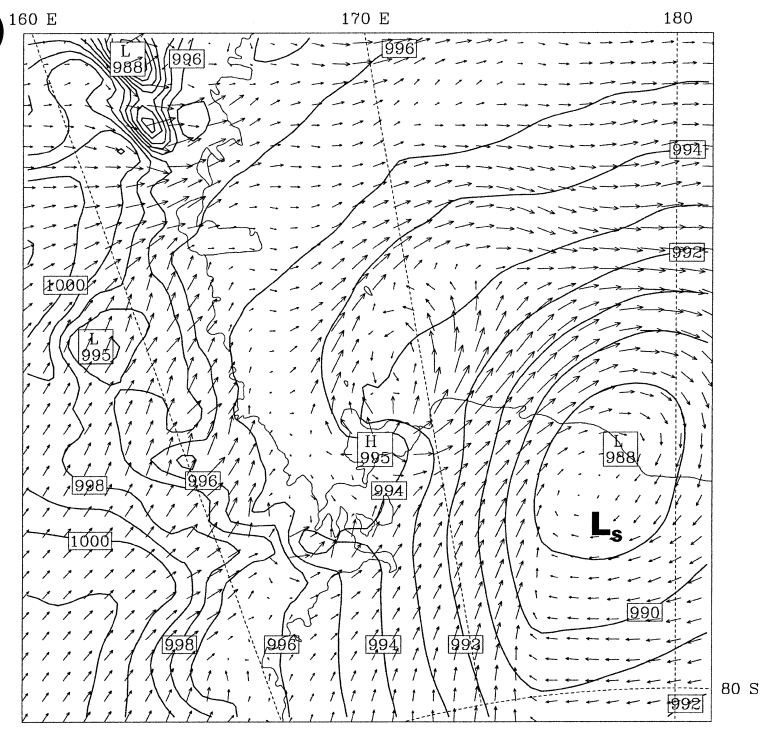

FIG. 14. (a) Hour 6, 1800 UTC 14 Jan 2001. Surface analyses for AMPS 10-km run beginning at 1800 UTC 14 Jan 2001. Sea level pressure (interval $=1 \mathrm{hPa}$ ) and surface wind are shown. Wind vector scaling $=17 \mathrm{kt}$ per distance between vector start points. For clarity, wind vectors are plotted for every other grid point. The positions of the observed surface lows are indicated by $L_{S}$ and $L_{N}$. (b) Same as in (a) but for hour 12, 0000 UTC 15 Jan. (c) Same as in (a) but for hour 18, 0600 UTC 15 Jan. (d) Same as in (a) but for hour 24, 1200 UTC 15 Jan. (e) Same as in (a) but for hour 30, 1800 UTC 15 Jan. 
clonic one coincident with the center of the lowest pressure and north of the western half of the island, and a weaker, anticyclonic one coincident with the zone of higher pressure east of the lee low and north of the eastern end of the island. The behavior of this dominant cyclonic circulation may be reflected in the actual case, as $\mathrm{L}_{\mathrm{N}}$ remained in this zone north of Ross Island for nearly 6 h (0000-0600 UTC 15 January) and hardly moved. Finally, note that the flow over the obstacle (Ross Island) has induced not only the lee trough/low, but also an upstream ridge along the island's southern boundary, near Windless Bight (location shown in Fig. 11). This is a commonly observed feature (e.g., O'Connor and Bromwich 1988; O'Connor et al. 1994).

By the final 10-km forecast time (hour 30, 1800 UTC 15 January; Fig. 14e) the main low has moved about $4^{\circ}$ east and is straddling the ice edge. It has strengthened slightly to $988 \mathrm{hPa}$, and this compares to the analyzed $992 \mathrm{hPa}$ for $\mathrm{L}_{\mathrm{S}}$. The southerly barrier wind flow around Ross Island has weakened with the southeasterly movement of the system, and thus the signal of the lee low has diminished. The lee trough and upwind ridge remain evident, however. The strongest lee-effect circulation is now detached from Ross Island and, in actuality, is anticyclonic. This circulation is centered in an area of slightly higher pressure about $70 \mathrm{~km}$ north of the island, and is evidenced in the surface observations at this time (not shown). Subsequent forecasts show that over time the lee low dissipates, with its circulations drifting northeastward and spinning down, as the main low distances itself.

Figures 15a-c offer a look at model-predicted 500$\mathrm{hPa}$ conditions during the forecast period examined above for the surface. These plots reflect the AMPS 30$\mathrm{km}$ grid run initialized at 1200 UTC 14 January. At 1800 UTC 14 January (hour 6), the starting time of the $10-\mathrm{km}$ forecast, the upper-level low associated with this event is positioned southwest of the western Ross Sea region (Fig. 15a). This center moves northeast over the next $12 \mathrm{~h}$ (Fig. 15b), providing enhanced upper-level support for surface development, and is quite similar to the revised $500-\mathrm{hPa}$ analysis shown in Fig. 3d. This coincides with the period of the most significant deepening of the observed and modeled surface lows (see Figs. 1, 14a-c). Lastly, by hour 30 (valid 1800 UTC 15 January), the 500-hPa low is centered just south of Ross Island, over Minna Bluff (Fig. 15c). Near-vertical alignment of the surface and 500-hPa features (Fig. 14e) is consistent with the filling of the observed low. It is noted that the $30-\mathrm{km}$ grid output examined does not show distinct shortwaves through the period. Although it cannot be known from the minimal upper-air data available, it is possible that such may have been associated with the multiple surface mesoscale low pressure developments that were observed.

\section{c. Discussion of the Polar MM5 performance}

As seen in Fig. 13, the first three model tracks evidence a system that has continuity from one forecast to
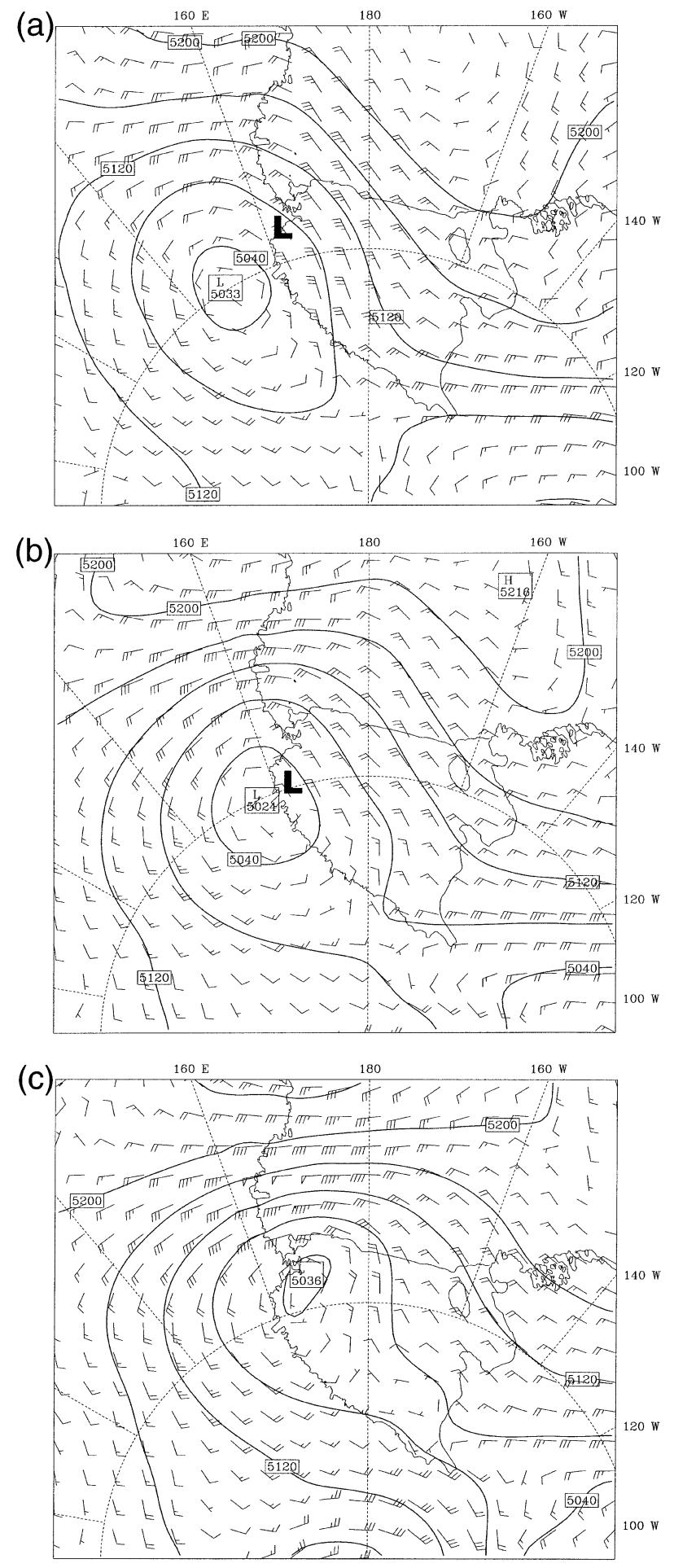

FIG. 15. (a) Hour 6, 1800 UTC 14 Jan. The 500-hPa analyses for AMPS 30-km run beginning 1200 UTC 14 Jan 2001. Heights (contour interval $=40 \mathrm{~m}$ ) and winds shown. Wind vectors: full barb $=10 \mathrm{kt}$ and half barb $=5 \mathrm{kt}$. For clarity, wind vectors are plotted for every fourth grid point. The bold $\mathrm{L}$ in (a) and (b) represents the location of the observed 500-hPa low, as shown in Figs. 3c and 3d, respectively. (b) Same as in (a) but for hour 18, 0600 UTC 15 Jan. (c) Same as in (a) but for hour 30, 1800 UTC 15 Jan. 


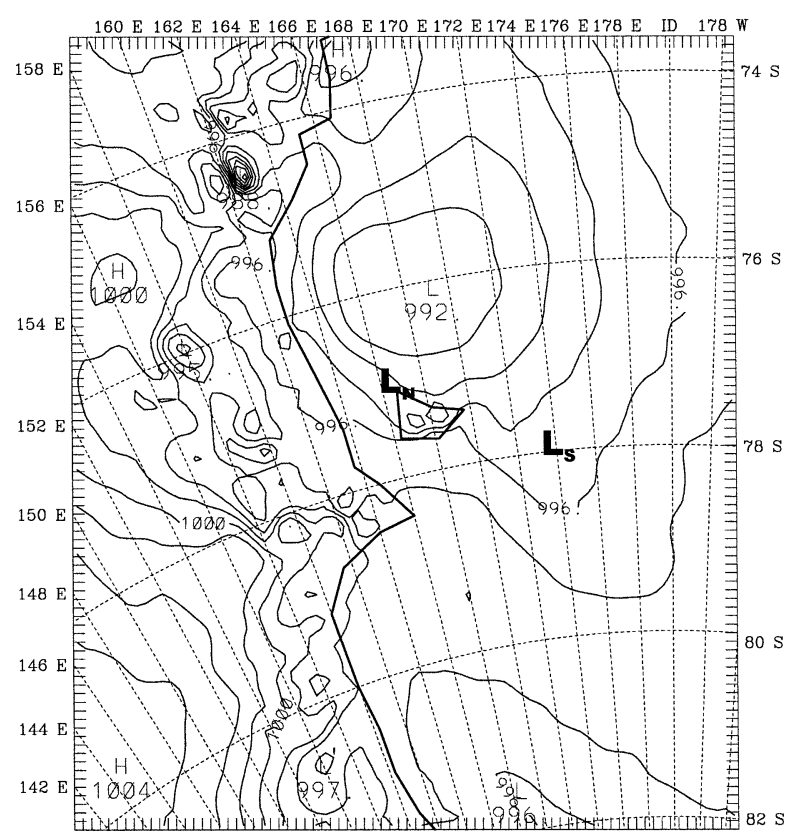

a.

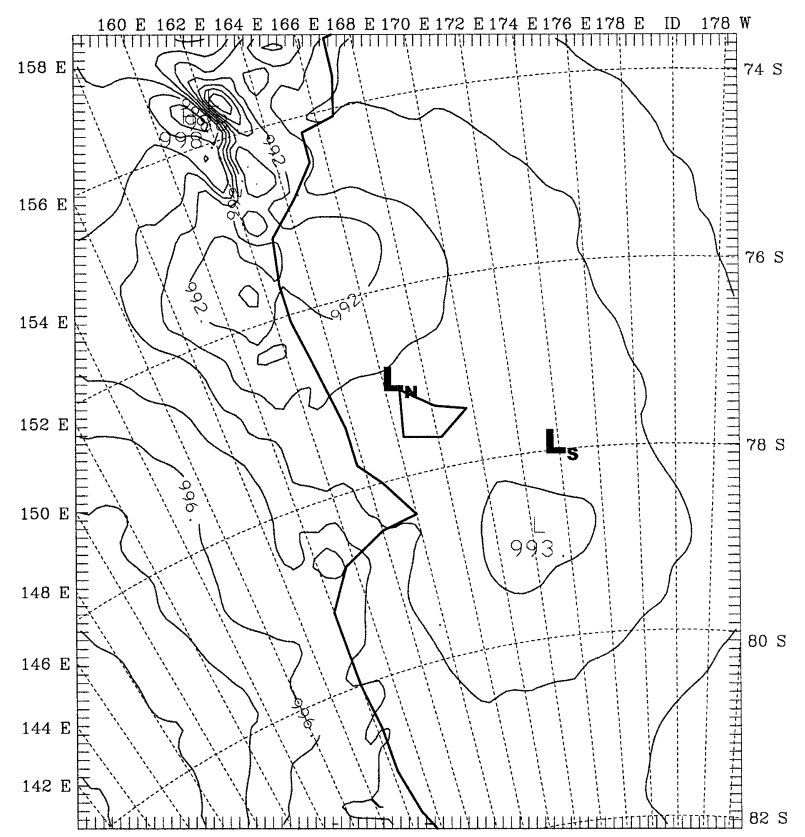

b.

FIG. 16. Hour 12 (0000 UTC 15 Jan) of AMPS forecast initialized at 1200 UTC 14 Jan using (a) AVN initial and boundary conditions and (b) ECMWF/TOGA initial and boundary conditions. The positions of the observed surface lows are indicated by $\mathrm{L}_{\mathrm{S}}$ and $\mathrm{L}_{\mathrm{N}}$.

another as it develops north of Ross Island and tracks southeastward. A jump, however, is reflected in the starting location of the last forecast track plotted (the 1800 UTC 15 January 10-km run). In Fig. 13, the label 18Z (fcst) points to the same time for the previous run (beginning at 0600 UTC 15 January). Comparing this position to the corresponding time of the 1800 UTC 15 January run (the beginning point), the discrepancy is seen. This occurs because in the 1200 UTC 15 January system (90- and $30-\mathrm{km}$ grids) initialization, a low aligned with the observed system $\left(\mathrm{L}_{\mathrm{S}}\right)$ is present in the AMPS initial conditions, which derive from the AVN. Thus, when the initial conditions contain features, they will be present in the forecast, at least for a while. Below, we examine the effect of the initial conditions by 1) using a different model than AVN to depict the initial and boundary conditions and 2) assimilating all available observations for the period.

\section{1) Additional Runs using ECMWF/TOGA}

Two additional runs were performed for the 0000 and 1200 UTC 14 January initializations using European Centre for Medium-Range Weather Forecasts (ECMWF) Tropical Ocean Global Atmosphere (TOGA) $2.5^{\circ} \times 2.5^{\circ}$ resolution global operational analysis data (henceforth, ECMWF/TOGA) obtained from NCAR to depict the initial and boundary conditions. These data were used because the upper-level conditions are similar to the adjusted values shown by the bold lines in Figs. $3 \mathrm{a}-\mathrm{d}$, with the upper-level low pressure center being farther north and stronger than in the AVN fields. It should be noted, however, that the ECMWF/TOGA data are at a much lower spatial resolution than AVN, and the temporal resolution is every $12 \mathrm{~h}$, as opposed to 6 $\mathrm{h}$ for AVN (this influences the lateral boundary conditions, which are imposed throughout the model run). However, the ECMWF/TOGA data are derived from the initial fields of the much higher resolution ECMWF global forecast model, which may be considered for providing initial and boundary conditions in future versions of AMPS.

Figure 16 compares the results of the AMPS 10-km domain runs using (a) AVN and (b) ECMWF/TOGA for hour 12 (0000 UTC 15 January) of the 1200 UTC 14 January model initialization. Inspection indicates significant differences between the two cases. The AMPS run using AVN initial and boundary conditions, as described earlier in the manuscript, resolves one area of low pressure (this is the same time step as is shown in Fig. 14b, reprinted here for comparative purposes). The run using ECMWF/TOGA initial and boundary conditions resolves two regions of low pressure connected by a trough, similar to the observations (shown at approximately the same time in Fig. 2c, 4 h earlier). The observed positions of $\mathrm{L}_{\mathrm{S}}$ and $\mathrm{L}_{\mathrm{N}}$ are shown in bold in Fig. 16. It appears that the run using the AVN initial and boundary conditions more accurately depicts $\mathrm{L}_{\mathrm{N}}$, while the run using the ECMWF/TOGA initial and boundary conditions more accurately depicts $\mathrm{L}_{\mathrm{S}}$. The authors plotted the tracks of the systems for both the AVN and ECMWF/TOGA initial and boundary conditions for both forecasts (0000 and 1200 UTC 14 Jan- 
uary; not shown). The results are similar: $\mathrm{L}_{\mathrm{N}}$ is more closely represented in the runs using AVN initial and boundary conditions, while $\mathrm{L}_{\mathrm{S}}$ is more closely captured in the runs using ECMWF/TOGA initial and boundary conditions. It is noteworthy that the storm tracks depicted by the runs using ECMWF/TOGA initial and boundary conditions closely resemble both the velocity and direction of the observed track of $\mathrm{L}_{\mathrm{S}}$ in both cases, however, being slightly to the south. The runs using AVN tend to overpredict the velocity of $L_{N}$.

In order to examine whether the modeled lows are shallow surface features resulting from katabatic winds and topography, or deeper, vertically integrated mesoscale cyclones, plots of geopotential height, vertical velocity, and vorticity fields were analyzed at the 700- and 500-hPa levels for the runs using both AVN and ECMWF/TOGA conditions. The evidence clearly indicates that the systems are vertically integrated throughout the lower troposphere, with the surface lows consistently appearing under the divergent flow areas of the upper-level troughs and being in zones of upward vertical velocity observed at 700 and $500 \mathrm{hPa}$.

\section{2) Additional runs assimilating all AVAILABLE OBSERVATIONS}

For the 14-16 January forecasts, approximately five surface observations in the area covered by the $10-\mathrm{km}$ grid made it into each real-time AMPS initialization. Using these, the AVN first-guess fields were objectively reanalyzed (Nuss and Titley 1994). As shown above, many more observations were potentially available. Therefore, additional runs were performed incorporating all surface observations examined for the Ross Sea and Ross Ice Shelf area; no additional upper-air observations were available. It was found that the impact of the additional observations on the forecast fields was very short lived. This is because the objective reanalysis scheme (i) uses only surface observations (in this case) and (ii) does not entail vertical correlations or multivariate balanced responses as in systems such as threedimensional variational data assimilation (3DVAR). While the latter will yield responses in variables other than those assimilated and at levels beyond the surface, the scheme used does not. Thus, signals in surface pressure (for example) in the reanalysis are not necessarily consistent with the 3D mass and wind fields and, thus, will not be supported dynamically. As a result, the impacts of surface observations can be short lived. The effects of assimilated surface observations that are clustered in a relatively small area (e.g., the $10-\mathrm{km}$ grid area) can also be advected out of that area over time. There is a premium, then, on upper-air observations over the Antarctic continent for assimilation into the mesoscale models attempting to forecast there. Even with relatively dense surface observations in certain areas, the limited-area forecast will rely mainly on the de- scription of surface features offered by the first-guess model (here the AVN).

Noting the importance of the upper-level fields, it is recognized that the AVN does ingest Advanced Microwave Sounding Unit (AMSU-A) radiances from the $\mathrm{Na}$ tional Oceanic and Atmospheric Administration-15 (NOAA-15) polar-orbiting satellite. This is done via 3DVAR. Assuming that the NOAA-15 Antarctic overpass of 0546 UTC 15 January made it into the AVN 0600 or 1200 UTC initialization, it is possible that this assisted in the correct placement of the low $\left(\mathrm{L}_{\mathrm{S}}\right)$ in the 10-km 1800 UTC 15 January forecast (Fig. 13), which begins $6 \mathrm{~h}$ after the AMPS 90-/30-km grids are initialized at 1200 UTC from the AVN first guess. It is hypothesized that the readily distinguishable cloud signatures that had developed by around 0600 UTC 15 January were picked up by the instrument; Fig. 2d reveals these for 0700 UTC 15 January (similar to 0546 UTC; not shown). Note that in earlier satellite images (i.e., Figs. 2a-c), a distinct low signature is not apparent. From the satellite measurements, the associated circulation would be derived in the assimilation process. Accordingly, satellite detection of cloud fields is beneficial to AVN (and AMPS) initializations. In the future it is envisioned that the AMPS MM5 will employ 3DVAR. This should enable AMPS to assimilate a host of nontraditional indirect observations as they come on-line (such as radiances or radio occultations) in a system that can produce internally consistent 3D responses in the background field and, thus, better initial conditions.

\section{Conclusions}

\section{a. Findings of the event analysis}

There is a complex, low pressure trough extending from TNB to the southeast past Ross Island. Many depressions are present within the trough. There are two primary depressions: $\mathrm{L}_{\mathrm{N}}$, which moves southward from the northern Ross Sea to Ross Island, and $\mathrm{L}_{\mathrm{S}}$, which propagates out of East Antarctica and moves east over Ross Island, merges with $\mathrm{L}_{\mathrm{N}}$, then moves $\mathrm{SE}$ across the Ross Ice Shelf before dissipating. Of the two, $\mathrm{L}_{\mathrm{S}}$ exerts the most influence on the sequence of events.

A katabatic event in TNB occurs from 1200 UTC 13 January through 1200 UTC 16 January. Perhaps this outbreak is triggered by the passing of an upper-level perturbance over southern Victoria Land, similar to that described in Carrasco and Bromwich (1995). The winds from this event contribute to the prominent frontogenesis associated with $\mathrm{L}_{\mathrm{S}}$ after it passes over Ross Island.

A cyclonically forced barrier wind event occurs after $\mathrm{L}_{\mathrm{S}}$ has moved to the SE of Ross Island, associated with strong winds and drifting snow observed at Williams Field on 15 January. However, no snowfall occurs toward the end of this event, most likely a result of lower temperature and humidity values observed in the lower 
troposphere, and a shift in the upper level $(\sim 700 \mathrm{hPa})$ winds at this time.

Weather observations at Williams Field indicate two periods of snowfall and low visibility during this study. The first, $\mathrm{W}_{\mathrm{X} 1}$, is probably a result of orographic lifting over Ross Island from the north, induced by $\mathrm{L}_{\mathrm{N}}$ and the upper-level support associated with $\mathrm{L}_{\mathrm{S}}$. The second, $\mathrm{W}_{\mathrm{X} 2}$, is most likely due to orographic lifting over Minna Bluff from the south, associated with the west (northward flowing) side of $\mathrm{L}_{\mathrm{S}}$ once it has moved well to the southeast of Ross Island.

\section{b. Findings of the Polar MM5 analysis}

In summary, for the event period AMPS produces a single mesoscale low, in contrast to the multiple mesoscale lows observed. The model system develops in TNB, tracks southeastward, and until 0600 UTC 15 January is most analogous to $\mathrm{L}_{\mathrm{N}}$. From approximately this time onward the model system, in agreement with the analyses, aligns with $\mathrm{L}_{\mathrm{S}}$, moves over the Ross Ice Shelf, and tracks east-southeastward. The forecast central pressures are slightly deeper than those analyzed.

\section{1) Strengths}

The AMPS 500-hPa forecasts and depictions support the scenario of surface low development in the western Ross Sea region through 14-16 January 2001. The evolution of the modeled upper-level conditions is consistent with the observed conditions, and the timing of mesoscale low deepening. In addition, the Polar MM5 shows skill in resolving features that are common to this unique region. The $10-\mathrm{km}$ model runs indicate areas of low (high) pressure to the north (south) of Ross Island, which result from strong barrier wind flow over and around the island (e.g., O'Connor and Bromwich 1988). The model also resolves katabatic flow from two prominent sources, TNB and the Byrd Glacier region south of Minna Bluff (e.g., Parish and Bromwich 1987).

\section{2) WEAKNESSES}

An examination of the performance of the Polar MM5 indicates that the modeled storm track relies heavily on the placement of upper-level forcing and the surface low by the NCEP global AVN model in the initialization. This is evident in the (final) 1200 UTC 15 January system initialization, in which a low aligned with the observed system is present in the AMPS initial (AVN derived) conditions. However, as indicated in the first three AMPS initializations for the event period, the AVN often does not accurately, or with sufficient precision, capture the signals of the key mesoscale features. To explore a fix for this, additional runs were made using ECMWF/TOGA operational analyses to simulate the initial and boundary conditions for AMPS. Comparison of the runs using AVN versus ECMWF/TOGA condi- tions revealed that there are significant differences in the placement and movement of surface mesoscale features. These features were found to be deep, vertically integrated systems, extending upward throughout the lower troposphere. In addition, other AMPS runs were performed in an attempt to improve the depiction of the mesoscale lows in the AMPS initialization by incorporating all known surface observations. This did not yield a significant, lasting forecast improvement, as the information in the surface observations does not change the first guess in a manner that was supported by the wind and mass fields reflecting other, unassimilated variables at different levels.

\section{c. Recommendations}

In the future, it may be worthwhile to consider running AMPS using initial and boundary conditions derived from a model other than AVN (e.g., the ECMWF global forecast model), perhaps in the context of a brief experiment. This may lead to a significant improvement in model skill, or at least would allow for a more thorough examination of the strengths and weaknesses of both the initialization model(s), and AMPS. Likewise, an enhanced real-time data stream of additional local/ regional data (i.e., from AWS sites, Automatic Geophysical Observatories, ships, rawinsondes, satellite measurements) for assimilation into AMPS using a variational approach (i.e., 3DVAR) would help to improve the initialization of mesoscale features. However, an increase in the volume of upper-air observations would likely benefit the system on a more consistent basis than would the ingest of more surface observations. The greatest potential for such data lies with satellite-derived measurements and products, as these would provide the best coverage over the continent and the Southern Ocean. Future versions of the AMPS system envision the introduction of the MM5 3DVAR system under development, and the system's exploitation of existing and new real-time satellite observation types.

The Franklin Island AWS was not operational during the period of this study. This site plays a critical role in resolving cyclones to the north of McMurdo, as it is the only offshore AWS in the $\sim 300 \mathrm{~km}$ distance between Ross Island and TNB. Had the station been working, the location and intensity of $\mathrm{L}_{\mathrm{N}}$ would have been more accurately determined throughout this analysis. At the time of this writing, the station has been restored to operational status. However, in the interest of future forecasting endeavors, it is recommended that the maintenance of this site be a priority task during the annual USAP field season.

Similarly, the Inexpressible Island (Manuela) AWS anemometer was not operational for the period of study. It is also suggested that this site be a maintenance priority. The wind measurements at Inexpressible Island are a reflection of the outflow from Reeves Glacier, an indicator of katabatic wind intensity and duration in 
TNB (e.g., Bromwich 1989b; Bromwich et al. 1993). This is important, as katabatic winds play an important role in the frequent cyclogenesis that occurs in the Ross Sea between TNB and Franklin Island [two to three mesoscale cyclones per week during a 2-yr study period (Carrasco and Bromwich 1996)].

Acknowledgments. This research is supported by the National Science Foundation, Office of Polar Programs, via a cooperative agreement with UCAR (Subcontract 501-22961), and by NASA (NAG5-9518). We would like to thank the Italian Antarctic Program for providing satellite imagery, and AWS, ship, and rawinsonde data; the Antarctic Meteorological Research Center in Madison (Matthew Lazzara) for providing AWS data and satellite composites; the Arctic and Antarctic Research Center at Scripps (Dan Lubin, Steve Hart) and McMurdo Station (Stephen Willey) for providing satellite imagery; the U.S. Coast Guard (Lt. April Brown, LCDR Jeff Jackson, Shawn McPhilamy), National Climatic Data Center (Axel Graumann), the Center for Ocean Atmospheric Prediction Studies (Shawn Smith), and Quark Expeditions (Erica Wikander) for providing ship observations; Augsburg University (Noel Petit) for providing AGO data; Long Term Ecological Research-McMurdo Dry Valleys (Thomas Nylen) for providing weather station data; the National Centers for Environmental Prediction for providing global analysis and reanalysis data; and Raytheon Polar Services (Marian Moyher, Andy Archer) for providing ship observations and satellite imagery. The speedy response of these organizations to requests for data is greatly appreciated, particularly the Italian program, the AMRC, and the AARC.

\section{REFERENCES}

Bromwich, D. H., 1989a: An extraordinary katabatic wind regime at Terra Nova Bay, Antarctica. Mon. Wea. Rev., 117, 688-95.

, 1989b: Satellite analyses of Antarctic katabatic wind behavior. Bull. Amer. Meteor. Soc., 70, 738-749.

, and J. J. Cassano, 2000: Recommendations to the National Science Foundation from the Antarctic Weather Forecasting Workshop. Byrd Polar Research Center Misc. Publ. M-42, The Ohio State University, Columbus, OH, 48 pp.
— , and J. J. Cassano, 2001: Meeting summary: Antarctic Weather Forecasting Workshop. Bull. Amer. Meteor. Soc., 82, 14091413.

— T. R. Parish, A. Pellegrini, C. R. Stearns, and G. A. Weidner, 1993: Spatial and temporal characteristics of the intense katabatic winds at Terra Nova Bay, Antarctica. Antarctic Meteorology and Climatology: Studies Based on Automatic Weather Stations, D. H. Bromwich and C. R. Stearns, Eds., Antarctic Research Series, Vol. 61, Amer. Geophys. Union, 47-68.

_ J. J. Cassano, T. Klein, G. Heinemann, K. M. Hines, K. Steffen, and J. E. Box, 2001: Mesoscale modeling of katabatic winds over Greenland with the Polar MM5. Mon. Wea. Rev., 129, $2290-2309$.

Carrasco, J. F., and D. H. Bromwich, 1995: A case study of a midtropospheric subsynoptic-scale cyclone that developed over the Ross Sea and Ross Ice Shelf of Antarctica. Antarct. Sci., 7, 199210.

— Bay and Byrd Glacier, Antarctica during 1991. Global Atmos.Ocean Syst., 5, 43-72.

Cassano, J. J., J. E. Box, D. H. Bromwich, L. Li, and K. Steffen, 2001: Verification of Polar MM5 simulations of Greenland's atmospheric circulation. J. Geophys. Res., 106, 33 867-33 890.

Castro, I. P., W. H. Snyder, and G. L. Marsh, 1983: Stratified flow over three-dimensional ridges. J. Fluid Mech., 135, 261-282.

Cooper, W. A., 1986: Ice initiation in natural clouds. Precipitation Enhancement-A Scientific Challenge, Meteor. Monogr., No. 43, Amer. Meteor. Soc., 29-32.

Guo, Z., D. H. Bromwich, and J. J. Cassano, 2003: Evaluation of Polar MM5 simulations of Antarctic atmospheric circulation. Mon. Wea. Rev., 131, 384-411.

Kalnay, E., and Coauthors, 1996: The NCEP/NCAR 40-Year Reanalysis Project. Bull. Amer. Meteor. Soc., 77, 437-471.

Nuss, W. A., and D. W. Titley, 1994: Use of multiquadric interpolation for meteorological objective analysis. Mon. Wea. Rev., 122, $1611-1631$.

O'Connor, W. P., and D. H. Bromwich, 1988: Surface airflow around Windless Bight, Ross Island, Antarctica. Quart. J. Roy. Meteor. Soc., 114, 917-938.

— - _ , and J. F. Carrasco, 1994: Cyclonically forced barrier winds along the Transantarctic Mountains near Ross Island. Mon. Wea. Rev., 122, 137-150.

Parish, T. R., and D. H. Bromwich, 1987: The surface windfield over the Antarctic ice sheets. Nature, 328, 51-54.

Phillpot, H. R., 1991: The derivation of $500 \mathrm{hPa}$ height from automatic weather station surface observations in the Antarctic continental interior. Aust. Meteor. Mag., 39, 79-86.

Stearns, C. R., and M. A. Lazzara, 1999: Six years of composite infra-red images south of Forty South at three hourly intervals. Abstracts, IUGG 99 Conf., Birmingham, United Kingdom, International Union of Geodesy and Geophysics, B119.

Toniazzo, A., 1994: The Antarctic katabatic wind and its interaction with synoptic scale circulations in the Ross Sea. Ph.D. thesis, University of Milan, $150 \mathrm{pp}$. 